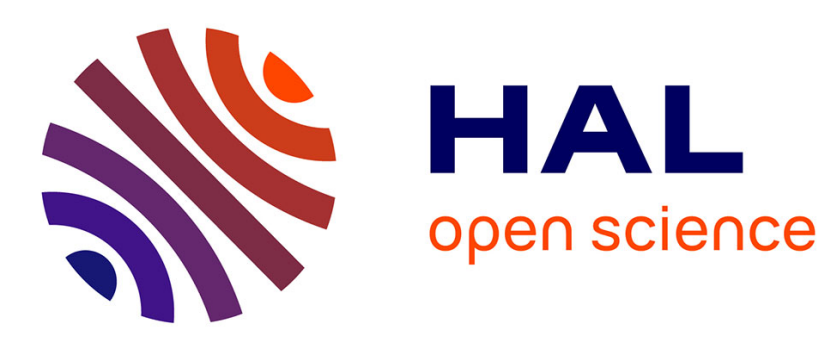

\title{
The 20S proteasome activator PA28 $\gamma$ controls the compaction of chromatin
}

Didier Fesquet, David Llères, Charlotte Grimaud, Cristina Viganò, Francisca

Méchali, Séverine Boulon, Olivier Coux, Catherine Bonne-Andrea, Véronique Baldin

\section{To cite this version:}

Didier Fesquet, David Llères, Charlotte Grimaud, Cristina Viganò, Francisca Méchali, et al.. The 20S proteasome activator PA28 $\gamma$ controls the compaction of chromatin. Journal of Cell Science, 2021, 134 (3), 10.1242/jcs.257717 . hal-03428214

\section{HAL Id: hal-03428214 \\ https://hal.umontpellier.fr/hal-03428214}

Submitted on 15 Nov 2021

HAL is a multi-disciplinary open access archive for the deposit and dissemination of scientific research documents, whether they are published or not. The documents may come from teaching and research institutions in France or abroad, or from public or private research centers.
L'archive ouverte pluridisciplinaire HAL, est destinée au dépôt et à la diffusion de documents scientifiques de niveau recherche, publiés ou non, émanant des établissements d'enseignement et de recherche français ou étrangers, des laboratoires publics ou privés. 


\title{
The 20 s proteasome activator PA28 $\gamma$ controls the compaction of chromatin
}

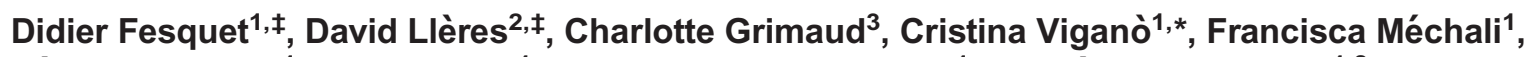 \\ Séverine Boulon ${ }^{1}$, Olivier Coux ${ }^{1}$, Catherine Bonne-Andrea ${ }^{1}$ and Véronique Baldin ${ }^{1, \S}$
}

\begin{abstract}
PA28 $\gamma$ (also known as PSME3), a nuclear activator of the 20S proteasome, is involved in the degradation of several proteins regulating cell growth and proliferation and in the dynamics of various nuclear bodies, but its precise cellular functions remain unclear. Here, using a quantitative FLIM-FRET based microscopy assay monitoring close proximity between nucleosomes in living human cells, we show that PA28 $\gamma$ controls chromatin compaction. We find that its depletion induces a decompaction of pericentromeric heterochromatin, which is similar to what is observed upon the knockdown of HP1 $\beta$ (also known as CBX1), a key factor of the heterochromatin structure. We show that PA28 $\gamma$ is present at HP1 $\beta$ containing repetitive DNA sequences abundant in heterochromatin and, importantly, that HP1 $\beta$ on its own is unable to drive chromatin compaction without the presence of PA28 $\gamma$. At the molecular level, we show that this novel function of PA28 $\gamma$ is independent of its stable interaction with the $20 \mathrm{~S}$ proteasome, and most likely depends on its ability to maintain appropriate levels of H3K9me3 and H4K20me3, histone modifications that are involved in heterochromatin formation. Overall, our results implicate PA28 $\gamma$ as a key factor involved in the regulation of the higher order structure of chromatin.
\end{abstract}

KEY WORDS: PA28 $\gamma$, Proteasome, HP1, Heterochromatin, FLIM-FRET

\section{INTRODUCTION}

In eukaryotic cells, the differential organization of chromatin into euchromatin and heterochromatin determines genome compaction and activity in the nucleus. Whereas euchromatin is a relaxed state that is generally transcriptionally active, heterochromatin exhibits a dense organizational state throughout interphase, with relatively low transcription levels and an enrichment of repetitive DNA sequences such as satellite repeats, transposable elements and ribosomal DNA (Lippman et al., 2004; Nishibuchi and Nakayama, 2014; Saksouk et al., 2015; Janssen et al., 2018). Heterochromatin is paramount to

${ }^{1}$ Centre de Recherche de Biologie cellulaire de Montpellier (CRBM), Université de Montpellier, CNRS, 34293 Montpellier, France. ${ }^{2}$ Institut de Génétique Moléculaire de Montpellier (IGMM), Université de Montpellier, CNRS, 34293 Montpellier,

France. ${ }^{3}$ Institut de Recherche en Cancérologie de Montpellier (IRCM), INSERM

U1194, Institut Régional du Cancer (ICM), Université de Montpellier, CNRS Route de Mende, 34293 Montpellier, France.

*Present address: Asst-Monza Ospedale san Gerardo, via Pergolesi 33, 20900

Monza, MB, Italy.

†These authors contributed equally to this work

§Author for correspondence (veronique.baldin@crbm.cnrs.fr)

(D) D.F., 0000-0001-5657-9689; D.L., 0000-0003-1630-8758; C.G., 0000-00017944-5931; S.B., 0000-0002-5350-7169; O.C., 0000-0001-8455-3849; C.B-A. 0000-0002-6882-0705; V.B., 0000-0001-8523-0494

Handling Editor: Caroline Hill

Received 27 November 2020; Accepted 3 December 2020 the stability of eukaryotic genomes. Indeed, loss of control over these repetitive DNA sequences, including mutations produced by the integration or excision of transposable elements and recombination between repeats, can lead to transcriptional perturbation and DNA recombination, all of which events are at the root of oncogenic transformation (Ayarpadikannan and Kim, 2014; Klement and Goodarzi, 2014).

Multiple pieces of evidence from genetic and cell biology studies point to an important involvement of the heterochromatin protein-1 (HP1) family of chromodomain proteins (Maison and Almouzni, 2004; Verschure et al., 2005) and trimethylation of histone H3 K9 (H3K9me3) (Martin and Zhang, 2005; Saksouk et al., 2015) and histone H4 K20 (H4K20me3) (Schotta et al., 2004; Oda et al., 2009; Beck et al., 2012; Bosch-Presegué et al., 2017) in establishing and maintaining heterochromatic states. These histone methylation marks serve as molecular anchors for HP1 proteins, notably HP1 $\beta$ (also known as CBX1), which are required for heterochromatin compaction and silencing (Lachner et al., 2001; Thiru et al., 2004; Dambacher et al., 2013; Bosch-Presegué et al., 2017; Machida et al., 2018). However, the mechanism by which HP1 folds chromatincontaining H3K9me3-H4K20me3 into higher-order structures has not been fully elucidated.

Proteasome-mediated protein degradation is a central pathway that controls the stability and function of numerous proteins in most cellular processes (Collins and Goldberg, 2017). Proteasomes comprise a family of protein complexes resulting from the association of different regulators/activators with the catalytic core, called the 20S proteasome (Rechsteiner and Hill, 2005; Coux et al., 2020). Among their many functions, it is now well established that proteasome complexes are associated with chromatin and enriched at specific sites in the genome (Geng and Tansey, 2012; Kito et al., 2020), thereby suggesting a direct role for chromatinassociated proteasome complexes in genomic processes (McCann and Tansey, 2014).

Among the nuclear 20S proteasome regulators, the homoheptamer PA28 $\gamma$ (also known as PSME3, REG $\gamma, 11 \mathrm{~S} \gamma$ or Ki antigen) (Ma et al., 1992; Wilk et al., 2000; Mao et al., 2008) promotes the proteasomal degradation of growth-related proteins including the cyclindependent kinase inhibitors p21 (CDKN1A), p19 (CDKN2D) and p16 (CDKN2A) and c-Myc (Chen et al., 2007; Li et al., 2007, 2015), as well as several important regulatory proteins including steroid receptor coactivator 3 (SRC-3; also known as NCOA3), SirT7 and p53 (Li et al., 2006; Sun et al., 2016; Zhang and Zhang, 2008). Consistent with this, and despite the fact that PA28 $\gamma-20 \mathrm{~S}$ proteasome complexes constitute only a minor fraction (less than 5\%) of the whole proteasome population (Fabre et al., 2014), PA28 $\gamma$ is important for cell growth and proliferation. Indeed, PA28 $\gamma$-knockout mice show a decrease in body size (Murata et al., 1999; Barton et al., 2004), and derived mouse embryonic fibroblast (MEF) cells display reduced growth and proliferation, increased apoptosis and a slower G1 to S- 
phase transition. Besides its role in the degradation of growth-related proteins, PA28 $\gamma$ contributes to the control of cell nuclear architecture, since it is involved in the regulation of the dynamics of various nuclear bodies, including Cajal bodies (CBs) (Cioce et al., 2006; Jonik-Nowak et al., 2018), nuclear speckles (NSs) (Baldin et al., 2008) and promyelocytic leukemia bodies (PMLs) (Zannini et al., 2009). PA28 $\gamma$ has also been linked to chromosome stability (Zannini et al., 2008) and DNA repair (Levy-Barda et al., 2011), suggesting a potential role of this proteasome activator in the regulation of chromatin structure.

In this study, we highlight an unsuspected, likely proteasomeindependent, function of PA28 $\gamma$ in the control of chromatin compaction. Our investigations reveal that PA28 $\gamma$ is associated with chromatin, notably with repetitive DNA sequences abundant in heterochromatin, and importantly, is required to sustain HP1 $\beta$-dependent chromatin compaction. Furthermore, we show that PA28 $\gamma$ is necessary to maintain the levels of the H3K9me3 and H4K20me3 heterochromatic marks, thereby establishing PA28 $\gamma$ as an important new regulator of heterochromatin structure.

\section{RESULTS}

\section{PA28 $\gamma$ controls chromatin compaction in living cells}

The involvement of PA28 $\gamma$ in the organization of intra-nuclear structures and the maintenance of chromosome stability suggests that PA28 $\gamma$ could also play a key role in the regulation of chromatin structure. To explore this hypothesis, we performed quantitative fluorescence lifetime imaging microscopy-Förster resonance energy transfer (FLIM-FRET) measurements of chromatin compaction at the nanometer-scale in living HeLa cells inactive or not for PA28 $\gamma$. For this, we established a stable CRISPR/Cas9 PA28 $\gamma$-knockout HeLa cell line (Fig. 1A), expressing either H2B-GFP alone (denoted $\mathrm{HeLa}^{\mathrm{H} 2 \mathrm{~B}-\mathrm{GFP}}-\mathrm{KO}-\mathrm{PA} 28 \gamma$ ) or both $\mathrm{H} 2 \mathrm{~B}-\mathrm{GFP}$ and mCherry-H2B (denoted $\mathrm{HeLa}^{\mathrm{H} 2 \mathrm{~B}-2 \mathrm{FPs}}-\mathrm{KO}-\mathrm{PA} 28 \gamma$ ). In these cell lines, PA28 $\gamma$ depletion affected neither H2B-GFP nor mCherry-H2B expression levels, as analyzed by immunoblot and microscopy approaches (Fig. S1A,B). FRET was measured between the fluorophore-tagged histones incorporated into the chromatin; in this assay an increase in FRET efficiency corresponds to an increase in the occurrence of close proximity $(<10 \mathrm{~nm})$ between nucleosomes (Lleres et al., 2009). In wild-type (WT) $\mathrm{HeLa}^{\mathrm{H} 2 \mathrm{~B}-2 \mathrm{FPs}}$ cells, a heterogeneous FRET efficiency map was apparent throughout interphase nuclei on representative images made with continuous pseudocolors (Fig. 1B). We found that the areas associated with the highest FRET values (red-orange population) decreased in KO-PA28 $\gamma$ cells (Fig. 1B). This effect was confirmed by the determination of the mean FRET efficiency percentage, which shows a substantial reduction in the level of chromatin compaction compared to the WT cells (Fig. 1C). As a positive control for chromatin decompaction, we treated $\mathrm{HeLa}^{\mathrm{H} 2 \mathrm{~B}-2 \mathrm{FPs}}$ cells with Trichostatin A (TSA), an inhibitor of histone deacetylases used to induce large-scale chromatin decompaction (Lleres et al., 2009; Otterstrom et al., 2019). As expected, after $24 \mathrm{~h}$ of TSA treatment, the mean FRET efficiency percentage dropped drastically, consistent with a massively decompacted interphase chromatin (Fig. S1C). By extracting the FRET efficiency distribution curves related to the FRET efficiency map of individual nuclei in both WT and KO-PA28 $\gamma$ cell lines, we found that the loss of PA28 $\gamma$ mainly caused a marked reduction of the high FRET population corresponding to high levels of chromatin compaction (Fig. 1D, black curve versus blue curve). In contrast, the low-FRET population corresponding to chromatin regions with the lowest degree of chromatin compaction remained poorly affected.
To ascertain that the observed chromatin decompaction was due to the absence of PA28 $\gamma$, we re-expressed (knocked in; KI) PA28 $\gamma$ in PA28 $\gamma-\mathrm{KO}$ cell lines (two different clones named KO/KI-WT\#6 and \#8 were selected) at a level comparable to that of the endogenous protein (Fig. 1E). Remarkably, for KO/KI-WT\#6 and \#8 clones, the FRET efficiency was restored to values similar to WT cells (Fig. 1F) indicating the re-establishment of normal chromatin compaction. Thus, these results show that PA28 $\gamma$ plays an important role in regulating the compaction of chromatin in interphase cells, with a particular impact on the most condensed chromatin regions.

\section{PA28 $\gamma$ controls chromatin compaction independently from its interaction with the 205 proteasome}

Given that PA28 $\gamma$ has functions that are both proteasome binding dependent (Li et al., 2007; Levy-Barda et al., 2011) and proteasome binding independent (Zannini et al., 2008; Zhang and Zhang, 2008 ), we asked whether the role of PA28 $\gamma$ in the regulation of chromatin compaction requires its interaction with the $20 \mathrm{~S}$ proteasome. For this purpose, a mutant of PA28 $\gamma$ deleted of its C-terminal 14 amino acids (named $\Delta \mathrm{C}$ ), which is unable to bind and to activate the 20S proteasome (Ma et al., 1993; Förster et al., 2005; Zhang and Zhang, 2008; Zannini et al., 2008), was stably expressed at a physiological level in $\mathrm{HeLa}^{\mathrm{H} 2 \mathrm{~B}-2 \mathrm{FPs}}-\mathrm{KO}-\mathrm{PA} 28 \gamma$ cells (named $\mathrm{KO} / \mathrm{KI}-\Delta \mathrm{C}$ ) (Fig. 2A). The inability of this PA28 $\gamma$ mutant to bind the $20 \mathrm{~S}$ proteasome was confirmed by co-immunoprecipitation experiments from cell extracts treated or not with the proteasome inhibitor MG132, which is known to increase the association between PA28 $\gamma$ and the 20S proteasome (Welk et al., 2016). As shown in Fig. 2B and Fig. S2, the 20S proteasome was detected by the presence of its $\alpha 4$ subunit (also known as PSMA7) in PA28 $\gamma$ immunoprecipitations from $\mathrm{HeLa}^{\mathrm{H} 2 \mathrm{~B}-2 \mathrm{FP}} \mathrm{WT}$ and $\mathrm{KO} / \mathrm{KI}-\mathrm{WT}$ cell extracts, but not in $\mathrm{KO} / \mathrm{KI}-\Delta \mathrm{C}$ and $\mathrm{KO}-\mathrm{PA} 28 \gamma$ cells. Chromatin compaction was then analyzed by FLIM-FRET in living asynchronous cells. We found that expression of the PA28 $\gamma-\Delta \mathrm{C}$ mutant restored the level of chromatin compaction in PA28 $\gamma-\mathrm{KO}$ cells to a FRET efficiency value $(24.7 \%)$ similar to that observed in WT cells $(23.03 \%$ ) (Fig. 2C). These results demonstrate that compaction of chromatin requires PA28 $\gamma$, but not its stable interaction with the $20 \mathrm{~S}$ proteasome.

\section{PA28 $\gamma$ controls pericentromeric heterochromatin compaction}

Since the loss of PA28 $\gamma$ mainly affects chromatin regions with a high FRET efficiency (Fig. 1D), we hypothesized that PA28 $\gamma$ might play a role in the regulation of highly compacted heterochromatin. To explore this possibility further, we used a previously described U2OS cell clone (F42B8) carrying lacO DNA repeats stably integrated within constitutive heterochromatin, at a pericentromeric region described as one of the most compacted chromatin domains in the nucleus (Jegou et al., 2009). This lacO array forms a single heterochromatic locus that can be visualized in cells following the transient expression of a GFP-LacI construct. The GFP signal allows us to measure the area occupied by the lacO locus and thus to quantify the variations of its accessibility and compaction state. As a control of measurable heterochromatin decompaction, we first examined the effect of the depletion of a known regulator of heterochromatin, HP1 $\beta$ (Maison and Almouzni, 2004; BoschPresegué et al., 2017), on lacO array compaction. These cells were transfected with siRNAs directed against HP1 $\beta$ (si-HP1 $\beta$ ) or luciferase (si-Luc), and with a GFP-LacI-expressing construct. The efficiency of si-HP1 $\beta$ was verified by immunoblotting (Fig. 3A, upper panel), and changes in heterochromatin compaction state 


\section{A}

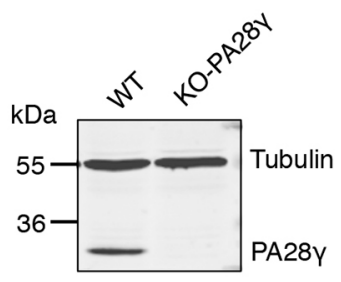

C

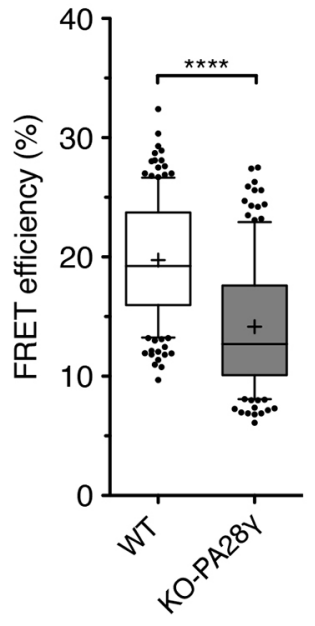

E

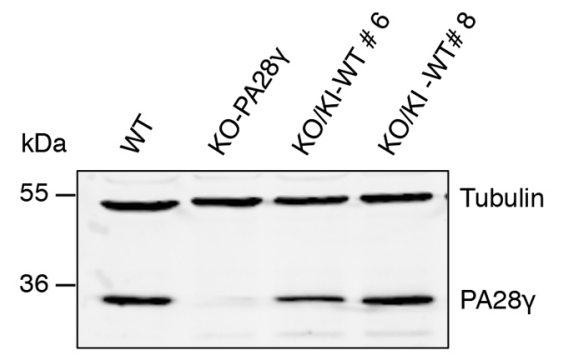

B

D
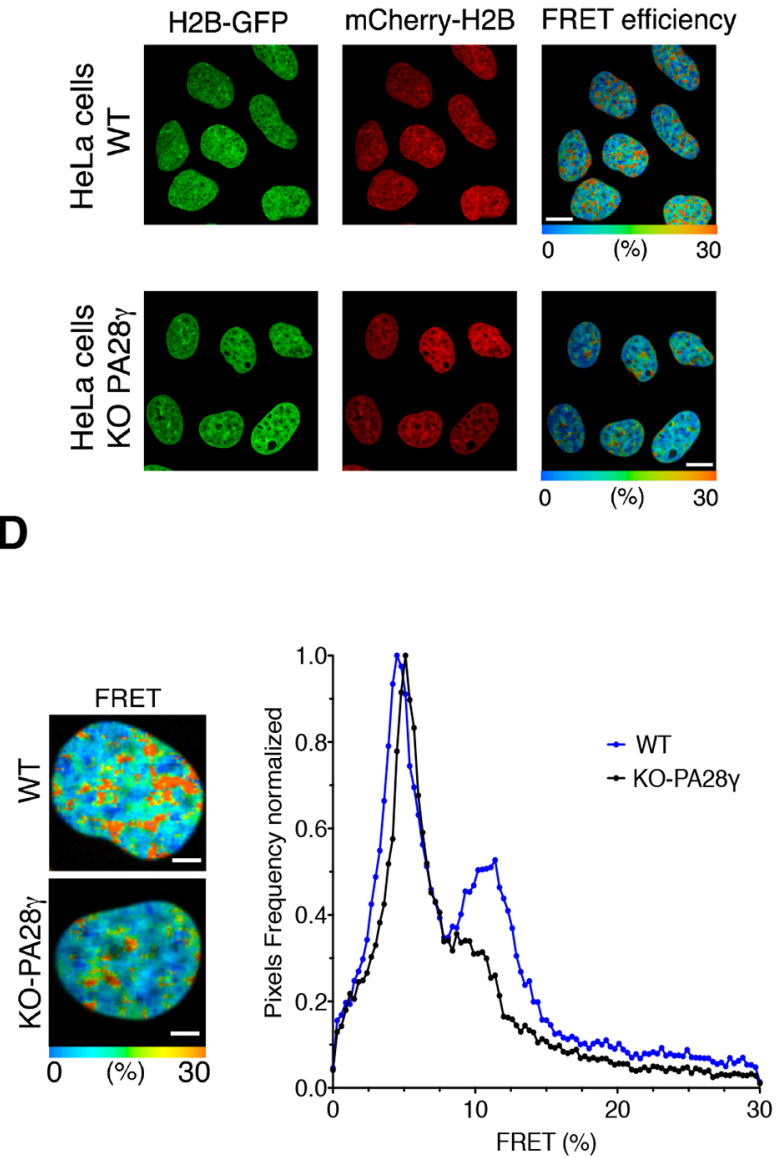

$\mathbf{F}$
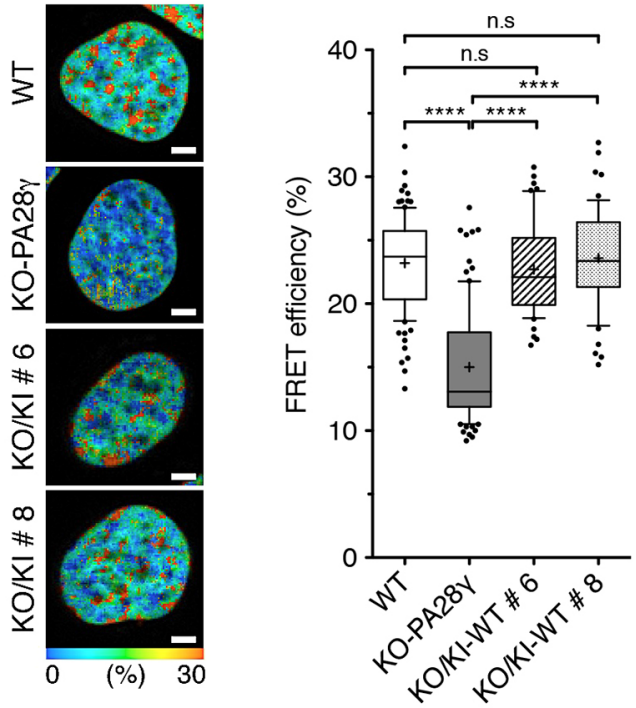

Fig. 1. See next page for legend.

were monitored $48 \mathrm{~h}$ post-transfection by fluorescence microscopy (Fig. 3A, lower panel). The $\mathrm{LacO}$ locus appeared as a small dot with a surface area that was not significantly affected by the transfection of si-Luc $\left(0.390 \pm 0.045 \mu \mathrm{m}^{2}\right.$ vs $0.370 \pm 0.052 \mu \mathrm{m}^{2}$ in control cells $)$. Upon HP1 $\beta$ knockdown, we observed a significant increase of the GFP-LacI dot surface area $\left(0.730 \pm 0.069 \mu \mathrm{m}^{2}\right)$. This corresponds to an expansion of the surface area occupied by the lacO DNA repeats due to heterochromatin decompaction (Fig. 3B). Then, we examined the effect of PA28 $\gamma$ knockdown (Fig. 3C,D). Upon PA28 $\gamma$-depletion we observed a significant increase in the GFPLacI dot surface area $\left(0.636 \pm 0.014 \mu \mathrm{m}^{2}\right.$ vs $0.370 \pm 0.052 \mu \mathrm{m}^{2}$ and $0.443 \pm 0.011 \mu \mathrm{m}^{2}$ in control cells and si-Luc-treated cells, 
Fig. 1. PA28 $\gamma$ controls chromatin compaction. (A) Immunoblot analysis of PA28 $\gamma$ expression level in total extracts from parental (WT) and PA28 $\gamma$-knockout (KO-PA28 $\gamma$ ) HeLa ${ }^{\mathrm{H} 2 \mathrm{~B}-2 \mathrm{FPs}}$ cells. Tubulin was used as a loading control. (B) FRET analysis in asynchronous interphase parental (WT) and PA28 $\gamma$ knockout (KO-PA28 $\gamma$ ) HeLa ${ }^{\mathrm{H} 2 \mathrm{~B}-\mathrm{FPs}}$ cells. FLIM-FRET measurements were performed and the spatial distribution of the FRET efficiency is represented in a continuous pseudocolor scale ranging from 0 to $30 \%$. Scale bars: $10 \mu \mathrm{m}$. (C) Statistical analysis of the mean FRET efficiency percentage in WT and KOPA28 $\gamma$ HeLa ${ }^{\text {H2B-2FPs }}$ nuclei, presented as box-and-whisker plots. The thick line represents median, the boxes correspond to the mean FRET values from the 25-75th percentiles of the median, with the whiskers covering the 10th-90th percentile range. The mean FRET value is indicated by a cross in each box. Data are from 4-6 independent experiments, the total number of cells analyzed is $n=154$ nuclei (WT) and $n=132$ nuclei (KO-PA28 $\gamma$ ). ${ }^{* * * *} P<0.0001$ (two-tailed unpaired Student's $t$-test). (D) Spatial distribution of the FRET efficiency (percentage) in representative WT and KO-PA28 $\gamma$ HeLa ${ }^{\text {H2B-2FPs }}$ nuclei. The FRET percentage distribution is depicted in a continuous pseudocolor scale ranging from 0 to $30 \%$ (left panel). Scale bars: $10 \mu \mathrm{m}$. FRET distribution graph shows distinct populations of FRET efficiency in WT and KO-PA28 $\gamma$ cells (blue and black curves, respectively) (right panel). (E) Immunoblot analysis of PA28 $\gamma$ expression level in total extracts from parental (WT), PA28 $\gamma$-knockout (KOPA28 $\gamma$ ) HeLa ${ }^{\mathrm{H} 2 \mathrm{~B}-2 \mathrm{FPs}}$ cells and two independent clones of HeLa ${ }^{\mathrm{H} 2 \mathrm{~B}-2 \mathrm{FPs}}$ cells knocked out for PA28 $\gamma$ in which wild-type PA28 $\gamma$ was stably re-expressed (KO/ $\mathrm{KI}-\mathrm{WT}$ \#6, KO/KI-WT \#8). Tubulin was used as a loading control. (F) Spatial distribution of the FRET efficiency (percentage) in representative WT, KO-PA28 and $\mathrm{KO} / \mathrm{KI}-\mathrm{WT}$ \#6, KO/KI-WT \#8 HeLa ${ }^{\mathrm{H} 2 \mathrm{~B}-2 \mathrm{FPs}}$ nuclei. The FRET percentage distribution is depicted as in D. Scale bars: $10 \mu \mathrm{m}$. Quantification of the mean FRET efficiency was represented as box-and-whisker plots as in C. Data represent are from 3 independent experiments, the total number of cells analyzed is $n=102$ nuclei (WT), $n=90$ (KO-PA28 $\gamma$ ), $n=53$ (KO/KI-WT \#6), $n=54$ (KO/KI-WT \#8). n.s, not significant, ${ }^{* * * *} P<0.0001$ (two-tailed unpaired Student's $t$-test).

respectively) (Fig. 3D). Thus, as observed in cells depleted for HP1 $\beta$, the pericentromeric heterochromatin is significantly decompacted in the absence of PA28 $\gamma$, supporting a role for PA28 $\gamma$ in the control of heterochromatin compaction.

The effect of PA28 $\gamma$ depletion on heterochromatin compaction prompted us to investigate whether PA28 $\gamma$ might associate with chromatin comprising repetitive sequences characteristic of heterochromatin, such as interspersed (HERV-K), pericentromeric (satellite II and $\alpha$ satellite) and major satellite (LINE-1) DNA repetitive sequences (Padeken et al., 2015). For this, quantitative chromatin immunoprecipitation (ChIP-qPCR) experiments were performed on parental (WT) versus KO-PA28 $\gamma$ U2OS cells, which had been previously characterized (see Fig. S3A and Jonik-Nowak et al., 2018). Since ChIP-qPCR experiments were normalized to the level of histone $\mathrm{H} 3$, we first verified that PA28 $\gamma$ depletion did not affect histone $\mathrm{H} 3$ expression levels by immunoblotting. As shown in Fig. S3B,C, no variation in expression level of histone $\mathrm{H} 3$ was observed in U2OS-KO-PA28 $\gamma$ cells. The same results were obtained for histone $\mathrm{H} 1$ and $\mathrm{HP} 1 \beta$ proteins. ChIP-qPCR experiments revealed that PA28 $\gamma$ was enriched at all four heterochromatin sequences tested (Fig. 3E), as was HP1 $\beta$ (Fig. S3D, Table S2). By comparison, we analyzed the PA28 $\gamma$ association with sequences located in the promoter of four actively transcribed genes $(G A P D H$, PSMB2, CCNA2 and CCNE2). Of the four euchromatin sequences tested, PA28 $\gamma$ was only detected at the promoter of the cyclin E2 gene, albeit at a much lower level (Fig. 3E), suggesting that its binding is not restricted to heterochromatin regions. Taken together, these results show that PA28 $\gamma$ is a chromatin-binding protein controlling the state of heterochromatin compaction.

\section{A fraction of PA28 $\gamma$ colocalizes with HP1 $\beta$}

The results described above led us to explore whether PA28 $\gamma$ colocalizes with regulators of heterochromatin establishment such as HP1 $\beta$. To verify this, we performed immunostaining against endogenous HP1 $\beta$ and PA28 $\gamma$ proteins in U2OS cells. As both are very abundant nuclear proteins and PA28 $\gamma$ displays a diffuse nuclear distribution as well (Masson et al., 2003; Wójcik et al., 1998; Cioce et al., 2006; Baldin et al., 2008), the soluble protein fraction was pre-extracted before fixation by treating the cells with $0.5 \%$ Triton X-100 in PBS (Guillot et al., 2004). Analysis of images acquired with a wide-field microscope suggested a potential colocalization between HP1 $\beta$ and PA28 $\gamma$ in some discrete areas of the nucleus (Fig. S4A, left panel, merged image and higher magnifications). Further analysis of HP1 $\beta$ and PA28 $\gamma$ proteins immunostaining, using a confocal microscope with Airyscan detection and image acquisition in $Z$-stacks followed by 3D reconstruction (Fig. S4B, left panel) suggested that indeed a small fraction of PA28 $\gamma$ colocalizes with HP1 $\beta$ with $\sim 32$ colocalization sites per nucleus in U2OS cells (Fig. S4B, right panel).

To strengthen this result, we used the in situ proximity ligation assay (is-PLA), which allows the detection of the close proximity between two proteins within cells (less than $40 \mathrm{~nm}$, i.e. likely to be an interaction) (Söderberg et al., 2006). Owing to the nuclear abundance of PA28 $\gamma$ and HP1 $\beta$, we first verified the specificity of this approach by testing the signal between PA28 $\gamma$ and one of its known partners, the $20 \mathrm{~S}$ proteasome, which is also highly abundant in the nucleus. Using antibodies raised against PA28 $\gamma$ and $\alpha 4$ (one subunit of the $20 \mathrm{~S}$ proteasome), is-PLA revealed a characteristic dotted pattern throughout the nuclei of U2OS cells (Fig. S4C, upper panel). Quantification of the number of PLA dots per nucleus (see Materials and Methods) indicated less than 60 dots (Fig. S4C, bar graph), a number consistent with the low amount of $20 \mathrm{~S}$ proteasome immunoprecipitated with PA28 $\gamma$ antibodies (see Fig. S2 and JonikNowak et al., 2018), supporting the notion that this signal is specific. Then, using both PA28 $\gamma$ and HP1 $\beta$ antibodies (Fig. 4), isPLA revealed on average 37 dots per nucleus (Fig. 4A, upper left panel and bar graph), a number in the same range as the number of colocalization sites $(\sim 32)$, as evidenced in Fig. S4B. Silencing of PA28 $\gamma$ expression with siRNAs (Fig. 4B), used as a negative control, abolished the PLA dots (Fig. 4A, lower panel and bar graph). Note that we also observed that a fraction of PA28 colocalized in part with HP1 $\alpha$ (also known as CBX5) by the is-PLA approach (Fig. S4D). Taken together, these results indicate that a small fraction of PA28 $\gamma$ is in close physical proximity (and thus is likely to interact either directly or indirectly) to a fraction of the heterochromatin-binding protein HP1 $\beta$.

\section{PA28 $\gamma$ is a chromatin compaction regulator as important as HP1 $\beta$}

As PA28 $\gamma$ ensures chromatin compaction and partially colocalizes with HP1 $\beta$ in cells, we wondered whether PA28 $\gamma$ might be as important in chromatin compaction as HP1 $\beta$. To address this question, we performed siRNA-mediated depletion of PA28 $\gamma$, $\mathrm{HP} 1 \beta$ or both proteins in $\mathrm{HeLa}^{\mathrm{H} 2 \mathrm{~B}-2 \mathrm{FPs}}$ cells (Fig. 5A) and compared the degree of chromatin compaction of these cells by FLIM-FRET approach (Fig. 5B,C). FRET measurements revealed a marked decompaction of chromatin upon PA28 $\gamma$-knockdown that was even stronger than upon HP1 $\beta$ depletion (Fig. 5B). This decompaction was correlated with the clear disappearance of the most compacted states of the chromatin within nuclei (Fig. 5C, left panel). To complete these data, we extracted the FRET efficiency distribution curves related to the FRET efficiency map from individual nuclei (Fig. 5C, right panel). While siRNA-Luc only caused an increase in the high-FRET population (Fig. 5C, right panel, blue curve) as compared to parental cells (Fig. 1D, right panel, blue curve), the quantitative analysis of the FRET distribution 
A

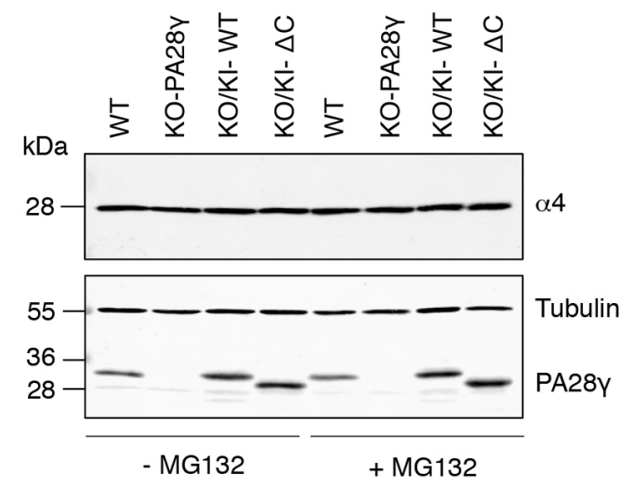

B

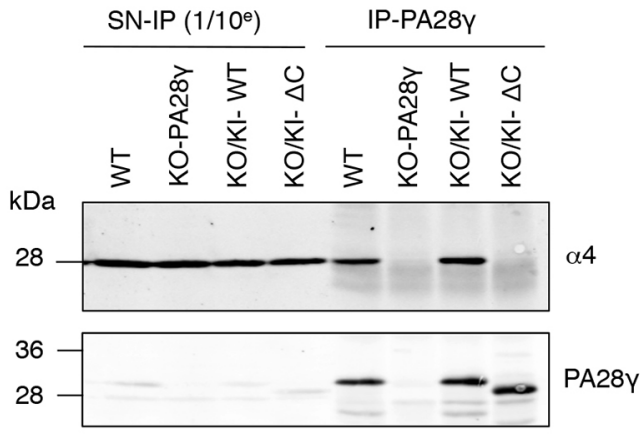

\section{C}
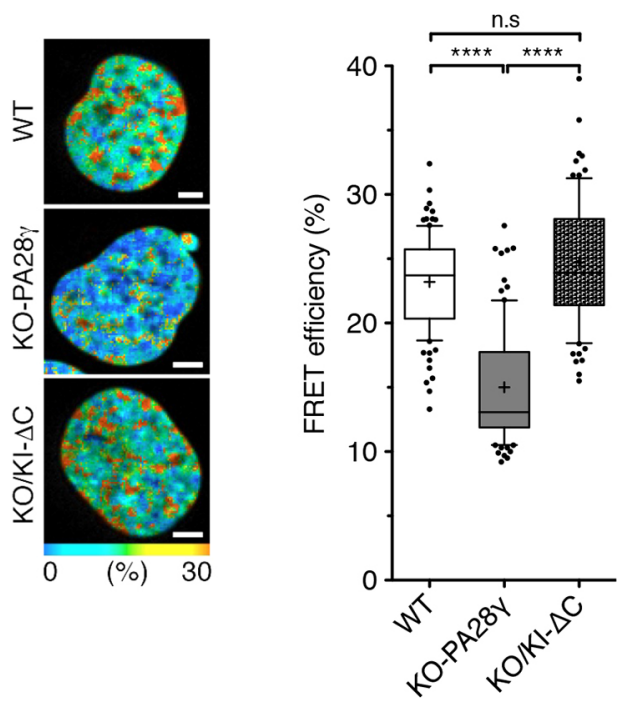

profiles revealed that PA28 $\gamma$-knockdown by siRNA had a stronger effect than the PA28 $\gamma$-knockout. This difference observed between PA28 $\gamma$-knockdown and PA28 $\gamma$-knockout might reflect potential compensatory mechanisms developed by the PA28 $\gamma$-KO cell line to preserve cellular homeostasis and viability. Interestingly, as already observed in Fig. 1, these results confirm that even in the presence of HP1 proteins the lack of PA28 $\gamma$ results in a strong decompaction of chromatin. This analysis also revealed a less-pronounced decompaction of the chromatin, with some persistent high-FRET values remaining, upon si-HP1 $\beta$ depletion than after si-PA28 $\gamma$ depletion (Fig. 5C, right panel, compare red and black curves). Most
Fig. 2. PA28 $\gamma$ interaction with the $20 \mathrm{~S}$ proteasome is not required for chromatin compaction. (A) Parental HeLa ${ }^{\mathrm{H} 2 \mathrm{~B}-2 \mathrm{FPs}}$ (WT), PA28 $\gamma$-knockout (KO-PA28 $\gamma$ ) cells and KO cells re-expressing the wild-type (KO/KI-WT\#8) form or the $\Delta \mathrm{C}$-mutant $(\mathrm{KO} / \mathrm{KI}-\Delta \mathrm{C})$ of PA28 $\gamma$ were treated, or not, for $2 \mathrm{~h}$ with MG132 $(25 \mu \mathrm{M})$, and whole-cell extracts were analyzed by immunoblotting using the antibodies indicated. (B) Cell extracts from cell lines treated with MG132 as in A were subjected to immunoprecipitation using anti-PA28 $\gamma$ antibodies. Immunoblots of one tenth of the supernatant (SN-IP, 1/10e) and the pull-down (IP-PA28 $\gamma$ ) from whole-cell extracts were probed with the antibodies indicated. (C) Spatial distribution of the FRET efficiency (percentage) in representative WT, KO-PA28 $\gamma$ and $\mathrm{KO}$ cells re-expressing the $\Delta \mathrm{C}$-mutant $(\mathrm{KO} / \mathrm{KI}-\Delta \mathrm{C})$ HeLa ${ }^{\mathrm{H} 2 \mathrm{~B}-2 \mathrm{FPs}}$ nuclei. The FRET percentage distribution is depicted as in Fig. 1D (left panel). Scale bars: $10 \mu \mathrm{m}$. Quantification of the FLIM-FRET measurements. Data are depicted as a box-and-whisker plot as in Fig. $1 \mathrm{C}$ from 3 independent experiments, the total number of cells analyzed is $n=102$ nuclei (WT), $n=90$ nuclei (KO-PA28 $\gamma$ ), $n=83$ nuclei $(\mathrm{KO} / \mathrm{KI}-\Delta \mathrm{C})$. n.s, not significant, ${ }^{* * * *} P<0.0001$ (two-tailed unpaired Student's $t$-test).

likely, the lower effect of HP1 $\beta$ knockdown might be explained by the presence of the other HP1 isoforms. Furthermore, the depletion of both PA28 $\gamma$ and HP1 $\beta$ had no additional effect on chromatin decompaction compared to depletion of PA28 $\gamma$ alone (Fig. 5B and $\mathrm{C}$, right panel, compare green and black curves). Altogether, these results strongly suggest that PA28 $\gamma$ is a key regulator of chromatin compaction that is as important as HP1 $1 \beta$, and that these two proteins might be involved in a similar regulatory pathway.

\section{PA28 $\gamma$ contributes to the maintenance of heterochromatin marks}

Besides the key role of HP1 proteins, methylation of histone $\mathrm{H} 3$ on K9 (H3K9me) (Maison and Almouzni, 2004; Grewal and Jia, 2007) and histone H4 on K20 (H4K20me) (Schotta et al., 2004; Shoaib et al., 2018) have been shown to be important for maintaining the ground state of chromatin structure. We therefore set out to investigate whether PA28 $\gamma$ could regulate the chromatin compaction state through H3K9 and H4K20 methylation in cells. To achieve this, we first examined, by western blotting, whether the loss of PA28 $\gamma$ might affect the steady-state levels of these epigenetic modifications. As shown in Fig. S5A, no significant change in the levels of $\mathrm{H} 3 \mathrm{~K} 9 \mathrm{me} 3$ was observed in U2OS-KO-PA28 $\gamma$ cells compared to WT cells. By contrast, PA28 $\gamma$ depletion led to a decrease ( 20\%) in the steady-state level of H4K20me3 (Fig. S5B). This was accompanied by a significant decrease $(\sim 40 \%)$ in H4K20me1 (Fig. S5B), which is a prerequisite for establishment of the H4K20me3 state (Tardat et al., 2007). These results led us to examine the variation of $\mathrm{H} 3 \mathrm{~K} 9 \mathrm{me} 3$ and $\mathrm{H} 4 \mathrm{~K} 20 \mathrm{me} 3$ at specific heterochromatin sequences. To this end, we carried out ChIP assays on parental (WT) and KO-PA28 U2OS cells using antibodies against $\mathrm{H} 3 \mathrm{~K} 9 \mathrm{me} 3$ and $\mathrm{H} 4 \mathrm{~K} 20 \mathrm{me} 3$, and performed quantitative (q)PCR using the same primers as in Fig. 3E. We observed a significant decrease in $\mathrm{H} 3 \mathrm{~K} 9 \mathrm{me} 3$ precipitation levels $(\geq 50 \%)$ at the specific heterochromatin sequences (Fig. 6A) that was not detected by immunoblot analyses on total cell extract (Fig. S5A). Note that the difference observed between immunoblot and ChIP-qPCR assay could result from a difference of sensitivity of both techniques using H3K9me3 antibodies. Since H3K9me3 serves as a molecular anchor for HP1 $\beta$, we checked its presence on these specific DNA sequences by ChIP-qPCR assay. Surprisingly, no obvious variation was observed for the sequences tested, except for the LINE-1 sequence (Fig. S5C), suggesting that either this decrease of $\mathrm{H} 3 \mathrm{~K} 9 \mathrm{me} 3$ level is not sufficient to destabilize HP1 $\beta$ binding and/or the involvement of other HP1 $\beta$ domains, such as its chromoshadow domain (CSD) (Zeng et al., 2010; Liu et al., 2017; Kumar and Kono, 2020), would facilitate its binding when chromatin is decondensed. We also 
A
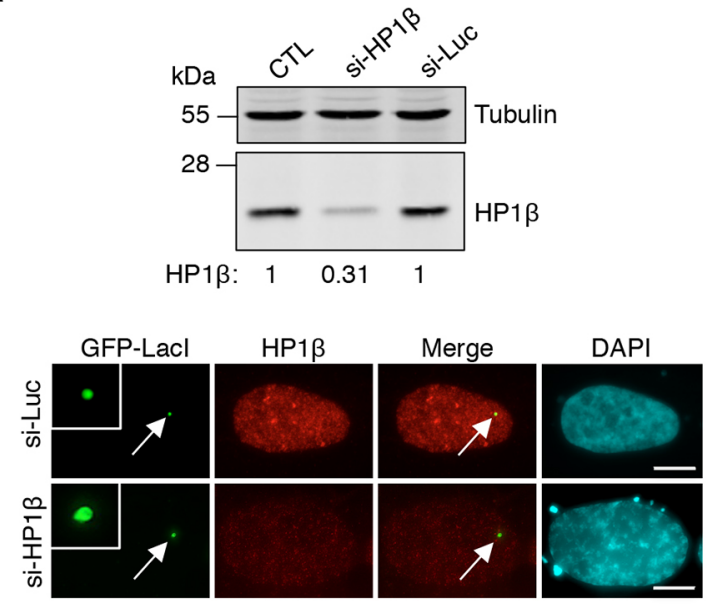

c
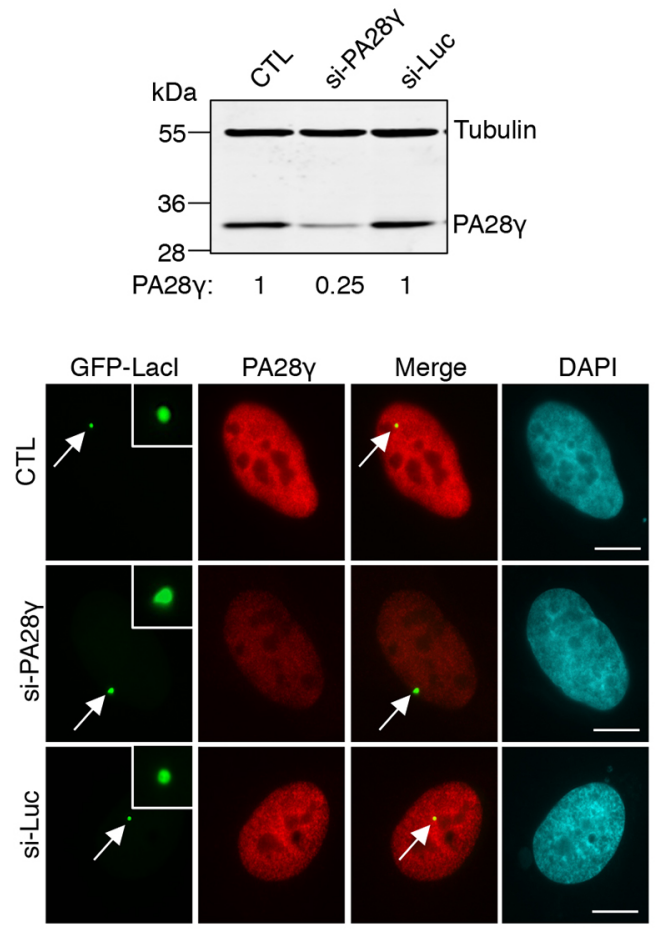

\section{E}

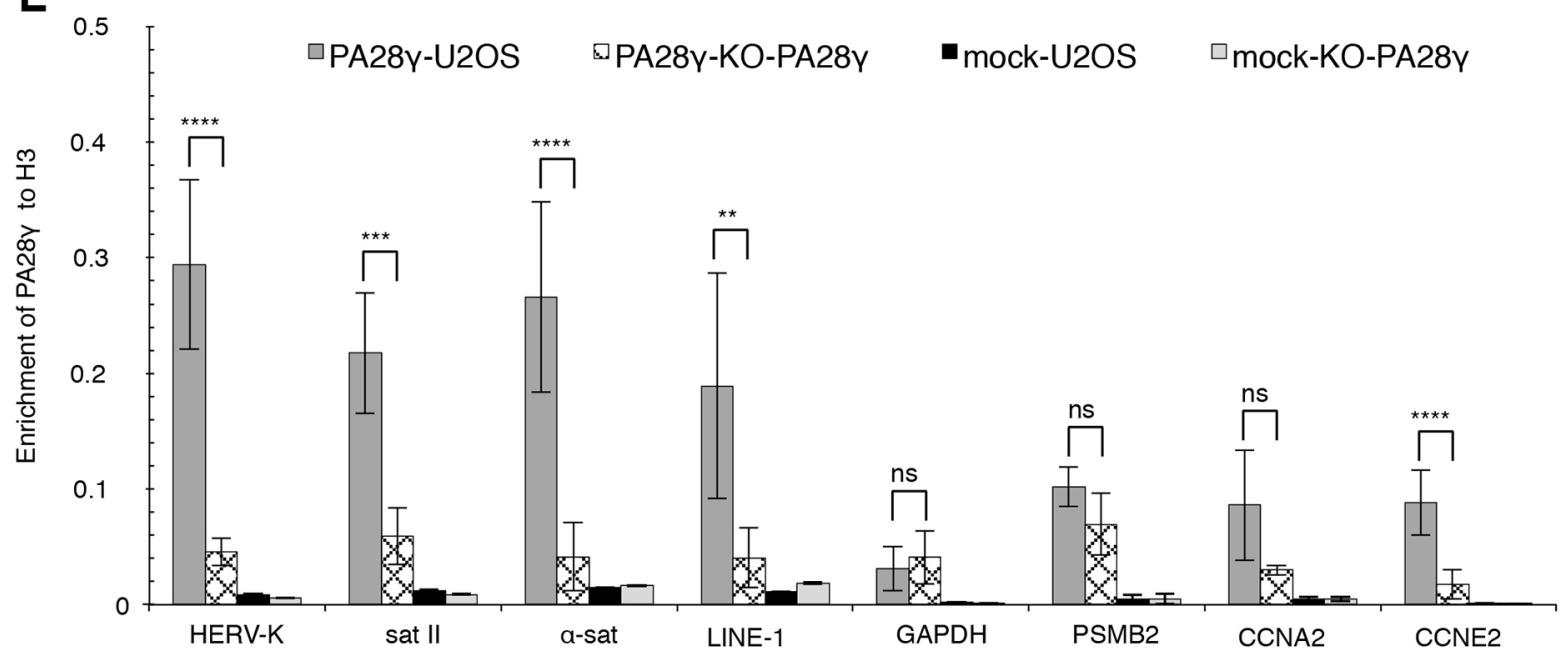

B

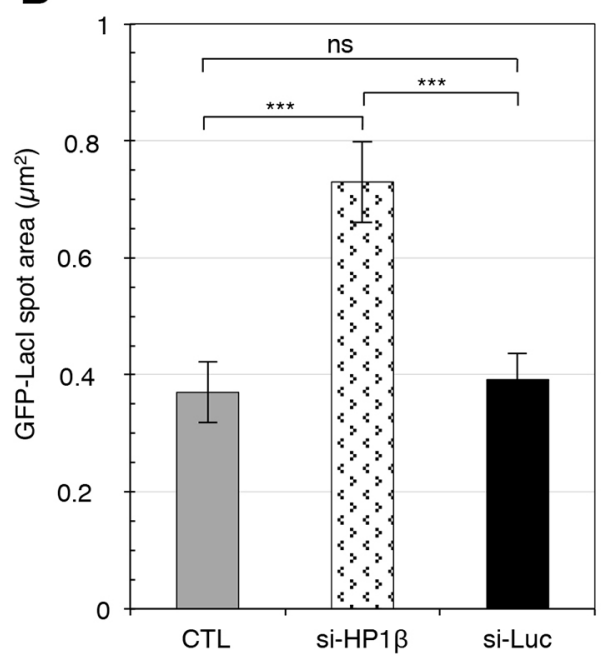

D

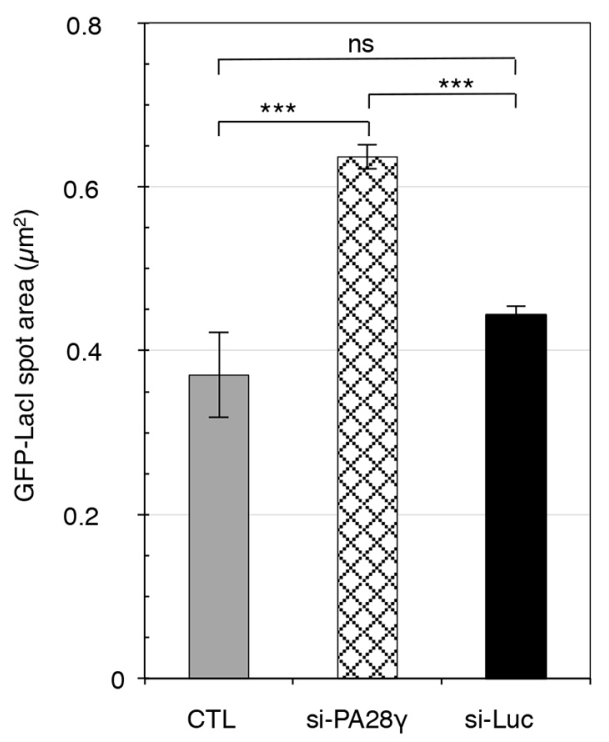

Fig. 3. See next page for legend. 
Fig. 3. PA28 $\gamma$ depletion induces a decompaction of pericentromeric heterochromatin and PA28 $\gamma$ is present on heterochromatin DNA

sequences. (A) U2OS-LacO cells, treated or not with si-HP1 $\beta$ or si-Luc, were transiently transfected with the GFP-Lacl construct the same day and were recovered $48 \mathrm{~h}$ later. Proteins were analyzed by immunoblotting. The relative abundance of HP1 $\beta$ in the extracts was quantified using ImageJ software and normalized to tubulin (upper panel). Cells on coverslips were immunostained with anti-HP1 $\beta$ (red) and the GFP signal was imaged in parallel (green). DNA was stained with DAPI (cyan). Representative fluorescence and immunofluorescence images of Z-stack projections of U2OS-LacO cells are shown. Magnified views of GFP-Lacl spot (arrows) are shown in insets. Scale bars: $10 \mu \mathrm{m}$. (B) Quantitative analysis of the decompaction of the LacO array $Z$-stack images were acquired on U2OS-LacO cells treated as in A, and the area of the GFP-Lacl signal was quantified on a Z-projection using ImageJ software (see Materials and Methods). Data represent the means \pm s.d. from three biological repeats, numbers of analyzed nuclei with GFP-Lacl spot were $n=30, n=28$ and $n=27$ in control cells (CTL), si-HP1 $\beta$ or si-Luc treated cells, respectively. ns, not significant, $P=0.2503$ (CTL/si-Luc), ${ }^{* * *} P=0.0003$ (CTL/

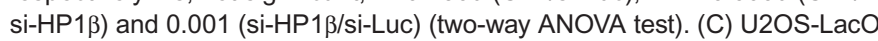
cells, treated or not with a si-PA28 $\gamma$ or si-Luc, were transiently transfected with GFP-Lacl construct the same day, recovered $48 \mathrm{~h}$ later and cells were analyzed as in A. Immunostaining was performed with antibodies raised against PA28 $\gamma$ (red) and the GFP signal was imaged in parallel (green). DNA was stained with DAPI (cyan). Representative fluorescence and immunofluorescence images of Z-stack projections of U2OS-LacO cells are shown. Magnified views of the GFP-Lacl spot (arrows) are shown in inserts. Scale bars: $10 \mu \mathrm{m}$. (D) Quantitative analysis of the decompaction of the LacO array. Z-stack images were acquired on U2OS-LacO cells treated as in C, and the area of the GFP-Lacl signal was quantified as in B. Data represent the means \pm s.d. from three biological repeats, numbers of analyzed nuclei with GFP-Lacl spot were $n=30, n=31$ and $n=29$ in control cells (CTL), si-PA28 or siLuc treated cells, respectively. ns, not significant, ${ }^{* *} P=0.0002$ (si-PA28 $\gamma /$ $\mathrm{CTL}$ ); ${ }^{* * *} P=0.00013$ (si-PA28 $\gamma / \mathrm{si}$-Luc) (Tukey's multiple comparisons test). (E) ChIP-qPCR analysis of PA28 $\gamma$ levels at different repetitive elements located in heterochromatin or in the promoter of actively transcribed genes (as indicated on the $x$-axis) in wild-type (WT) versus KO-PA28 $\gamma$ U2OS cells (right panel). Data are represented as relative enrichment of PA28 $\gamma$ antibody versus histone $\mathrm{H} 3$ control, as shown on the $y$-axis. Data are means \pm s.e.m. $(n=5)$. ns, not significant $(P=0.42531, P=0.18602, P=0.2395$ for GAPDH, PSMB2 and CCNA2, respectively), ${ }^{*} P<0.01$ ( $P=0.0046$, LINE-1), ${ }^{* *} P<0.001(P=0.00011$, Sat II), ${ }^{* * *} P<0.0001\left(P=2.09 \times 10^{-5}, P=5.15 \times 10^{-5}\right.$ and $P=2.08 \times 10^{-7}$ for HERV-K, $\alpha$-Sat and CCNE2, respectively) (two-tailed unpaired Student's $t$-test).

confirmed, by ChIP-qPCR assay, the substantial decrease of H4K20me3 ( $\geq 60 \%)$ on the same heterochromatin DNA sequences in KO-PA28 $\gamma$ versus WT U2OS cells (Fig. 6B).

We also investigated whether the loss of PA28 $\gamma$ induced a change of $\mathrm{H} 3 \mathrm{~K} 4 \mathrm{me} 3$, a modification considered as an epigenetic biomarker of transcription activation (Howe et al., 2017). No significant variation in $\mathrm{H} 3 \mathrm{~K} 4 \mathrm{me} 3$ levels was detected by immunoblot analyses on total cell extracts (Fig. S5D). This absence of variation was confirmed by ChIP-qPCR assay using primers on which a significant decrease of $\mathrm{H} 3 \mathrm{~K} 9 \mathrm{me} 3$ and/or H4K20me3 was observed (Fig. S5E), suggesting that PA28 $\gamma$ depletion has no significant impact on the transcription of the sequences tested. These results are in line with previous data showing that PA28y knockdown has no impact on the global transcription level (Cioce et al., 2006; Baldin et al., 2008), and our results indicating no variation in the transcription of the heterochromatin DNA sequences by RT-qPCR (data not shown).

The importance of H4K20me1, H4K20me3 and chromatin compaction in cell cycle progression and in the regulation of DNA replication (Brustel et al., 2017; Shoaib et al., 2018) prompted us to examine whether the loss of PA28 $\gamma$ might impact on cell cycle progression. To this end, parental (WT) and PA28 $\gamma$-depleted (KOPA28 $\gamma$ ) U2OS cells were synchronized with a double-thymidine block and then released from the G1/S transition before analysis for cell cycle progression by DNA content analysis using flow cytometry (Fig. 6C). Our data indicate that cells lacking PA28r entered into early S-phase at the same time after release as parental U2OS cells, but progressed faster and exited S-phase earlier compared to the wild-type U2OS cells (Fig. 6C, left panel). Consistent with this, KO-PA28 $\gamma$ cells showed an earlier entrance into G2 phase (Fig. 6C, right panel). This shortening of S phase $(\sim 1 \mathrm{~h})$ in KO-PA28 cells was confirmed by immunoblotting using cell cycle markers including cyclin E (a marker of G1 to S-phase transition) and the phosphorylation of histone $\mathrm{H} 3$ on serine 10 (a mitosis marker) (Fig. S6). Altogether, these results suggest that the chromatin decompaction and alterations in the levels of heterochromatin histone marks upon loss of PA28 $\gamma$ are not toxic per se, but accelerate S-phase progression, likely by favoring accessibility of the mostcompact chromatin regions to the replication machinery.

\section{DISCUSSION}

This study provides several pieces of evidence that PA28 $\gamma$, which is known as a nuclear activator of the $20 \mathrm{~S}$ proteasome, is also an essential regulator of chromatin structure.

We demonstrate that PA28 $\gamma$ plays a key role in the process of chromatin compaction by showing that the depletion of PA28 $\gamma$, by knockout and/or knockdown approaches, (1) induces a decompaction of the highly structured fraction of the chromatin, even in the presence of HP1 proteins, as visualized in living cells with our quantitative chromatin compaction assay, and (2) causes the decompaction of lacO DNA repeats integrated into a pericentromeric heterochromatin domain. As summarized in Fig. 7, we show that PA28 $\gamma$ is present on chromatin regions enriched for HP1 $\beta$ and contributes to the maintenance of heterochromatin features, such as $\mathrm{H} 3 \mathrm{~K} 9$ and H4K20 trimethylation.

A striking result of our study is that the chromatin structural role of PA28 $\gamma$ and its impact on the compaction of heterochromatin is as important as HP1 $\beta$, which is considered as a key regulator of heterochromatin domains and maintenance. We find that a small fraction of PA28 $\gamma$ colocalizes with HP1 $\beta$ in the nucleus, and the difficulty of detecting this colocalization suggests that it could occur in dynamic and/or transient structures. Interestingly, recent studies show that HP1 proteins have the capacity to form liquid-like droplets (also called condensates) resulting from a liquid-liquid phase separation (LLPS) mechanism (Larson et al., 2017; Strom et al., 2017). This property facilitates the enrichment of transient complexes that could be rapidly assembled and disassembled, and the exchange of various proteins required for heterochromatin compaction. Although recent results suggest that heterochromatin maintenance is independent of liquid droplet formation of HP $1 \alpha$ in mouse chromocenters and rather involves collapsed chromatin globules, HP1 proteins form transient droplets in the cells that could participate in the structure of chromatin subcompartments (Erdel et al., 2020). Considering this point, it is important to underline the fact that PA28 $\gamma$ is detected in various membraneless compartments such as NS, CB and PML bodies, considered to be liquid-like protein droplet organelles (Erdel and Rippe, 2018; Sawyer et al., 2019). Although the mechanism by which PA28 $\gamma$ is recruited into these nuclear bodies still remains to be unraveled, the interaction of PA28 $\gamma$ with specific proteins present in these condensates plays a crucial role in the control of their dynamics (Cioce et al., 2006; Zannini et al., 2009; Jonik-Nowak et al., 2018). For example, the interaction of PA28 $\gamma$ with Chk2, a cell cycle checkpoint kinase that localizes in PML bodies, is required for the control of PML body number (Zannini et al., 2009). In this context, the capacity of HP1 
A

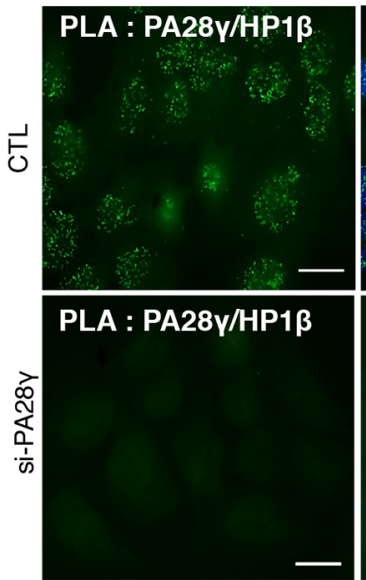

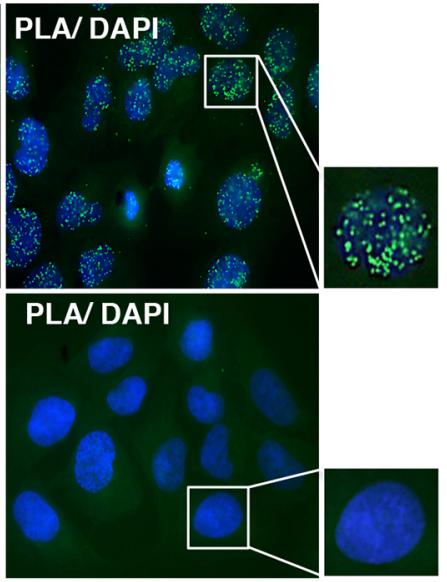

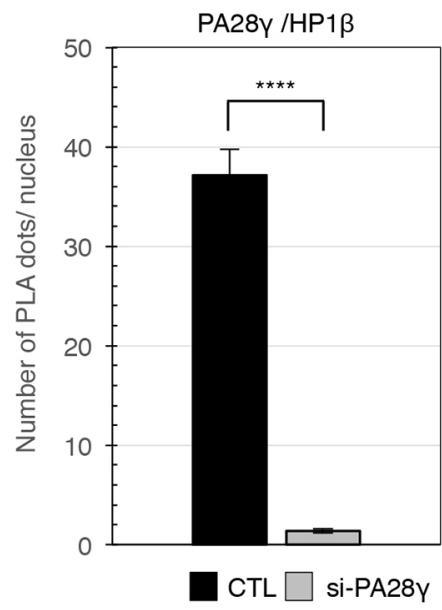

B

Fig. 4. A fraction of PA28 $\gamma$ colocalizes with HP1ß in U2OS cells. (A) Control (CTL) or si-PA28 $\gamma$ treated U2OS cells were subjected to is-PLA using primary antibodies directed against HP1 $\beta$ and PA28 $\gamma$, and DNA stained with DAPI. Positive PLA signals appear as green dots and higher magnification views of a nucleus are shown (left panel). Scale bars: $10 \mu \mathrm{m}$. Quantification of PLA dots was carried out using an ImageJ macro (see Materials and Methods). The number of PLA dots per nucleus for HP1 $1 \beta-P A 28 \gamma$ interaction in control (CTL) or si-PA28 $\gamma$ treated cells is shown graphically (right panel). Data represent the mean \pm s.d. from 3 independent experiments, the number of cells analyzed is $n=78$ and $n=45$ in control and si-PA28 $\gamma$ treated cells, respectively. ${ }^{* \star \star *} P=0.0001$ (two-tailed unpaired Student's $t$-test). (B) Immunoblot analysis of PA28 $\gamma$ expression level in total extracts of U2OS cells treated or not with si-PA28 $\gamma$, used for in situ proximity ligation assay (is-PLA). Tubulin was used as a loading control. The relative abundance of PA28 $\gamma$ in the extracts was quantified using ImageJ software.

proteins to form condensates that could participate in the transient enrichment of PA28 $\gamma$ in specific domains of the chromatin might facilitate the establishment of the PA28 $\gamma$ interaction with proteins required for chromatin compaction.

How PA28 $\gamma$, which has no known enzymatic activity, could favor proper maintenance of chromatin structure is still an open question. Our results suggest that the function of PA2 $8 \gamma$ function in chromatin compaction is likely independent of its proteasome-regulatory function, since a PA28 $\gamma$ mutant with its $\mathrm{C}$-terminal portion deleted still promotes chromatin compaction. Indeed, the binding of the C-terminal extremity of PA28 activators to the $20 \mathrm{~S} \alpha$-ring is the first essential step for complex formation and activation of the proteasome (Förster et al., 2005). Although we cannot at this stage exclude the possibility of a transient interaction of PA28 $\gamma$ mutant with the 20S proteasome in cells, a direct regulation of chromatin compaction by a PA28 $\gamma$-dependent proteolysis event seems unlikely. Therefore, since PA28 $\gamma$ depletion induces a significant decrease of H3K9me3 ( $\geq 50 \%)$, H4K20me1 $(\geq 40 \%)$ and H4K20me3 ( $\geq 60 \%)$, it is conceivable that PA28 $\gamma$ acts either by facilitating the function of the lysine methyltransferases Suv39h, PR-Set7 or Suv4-20h responsible for H3K9 tri-methylation, H4K20 monomethylation and H4K20 trimethylation, respectively, or by inhibiting specific histone demethyltransferases, or other protein complexes involved in chromatin remodeling. It is interesting to note that the PA28 $\gamma$ interactome contains two major interactors, BRD9 and SMARCA4 (BRG1) (Jonik-Nowak et al., 2018), which are two subunits of a newly defined ATP-dependent chromatin remodeling complex (Alpsoy and Dykhuizen, 2018). However, the physiological significance of these interactions in the new function of PA28 $\gamma$ in chromatin compaction remains to be determined.

Chromatin alterations occurring upon loss of PA28 $\gamma$ neither impact cell viability nor induce a strong phenotype, as observed upon HP1 $\beta$ depletion in MEF cells (Bosch-Presegué et al., 2017) or in HP1-triple knockout in hepatocytes (Saksouk et al., 2020). However, our data reveal a change in cell cycle progression with a decrease in S-phase duration, suggesting that the accessibility and/ or the progression of the replication machinery could be facilitated by the decompaction of the most condensed chromatin domains.

It is noteworthy that previous studies have reported the consequences of PA28 $\gamma$ depletion on chromatin-related processes, such as centrosome maintenance and chromosomal stability (Zannini et al., 2008) and DNA repair (Levy-Barda et al., 2011). Our present observations suggest that the role of PA28 $\gamma$ in the regulation of chromatin structure could be the common mechanism that links these processes to PA28 $\gamma$. Indeed, alterations in $\mathrm{H} 3 \mathrm{~K} 9$ methylation, as observed in PA28 $\gamma-\mathrm{KO}$ cells, results in an increase in chromosome segregation errors, which have been linked to a role of pericentromeric heterochromatin in the proper assembly of centromeres (Peters et al., 2001; Peng and Karpen, 2009). The reported increase of aneuploidy under PA28 $\gamma$ knockdown (Zannini et al., 2008) could also result from the decrease of H3K9me3 observed in our study. In the same vein, PA28 $\gamma$ depletion does not spontaneously induce DNA damage, but leads to an increase of cellular radiomimetic sensitivity and a substantial delay in DNA double-strand-break (DSBs) repair (Levy-Barda et al., 2011). This effect could also result from the contribution of PA28 $\gamma$ towards maintaining appropriate levels of $\mathrm{H} 3 \mathrm{~K} 9 \mathrm{me} 3$ and $\mathrm{H} 4 \mathrm{~K} 20 \mathrm{me} 1 / 3$ since these histone modifications have been involved in promoting or inhibiting the recruitment of specific repair proteins, which directly affect DNA damage repair efficiency (Price and D'Andrea, 2013).

Altogether, our data reveal that PA28 $\gamma$ is a novel and crucial factor in the regulation of chromatin compaction. Although much remains to be understood regarding its exact contribution to this process, our findings undoubtedly open new avenues of research for a deeper understanding of the complex mechanisms that control chromatin organization.

\section{MATERIALS AND METHODS}

\section{Plasmids}

For Cas9-mediated gene disruption, guide RNA (5'-GGAAGTGAAGCTCAAGGTAGCGG-3') targeting PA28 $\gamma$ (PSME3) was selected using ChopChop (https://chopchop.cbu.uib.no/) and oligonucleotides were subcloned into pMLM3636 (Addgene plasmid \#43860, deposited by Keith Joung) and 
A
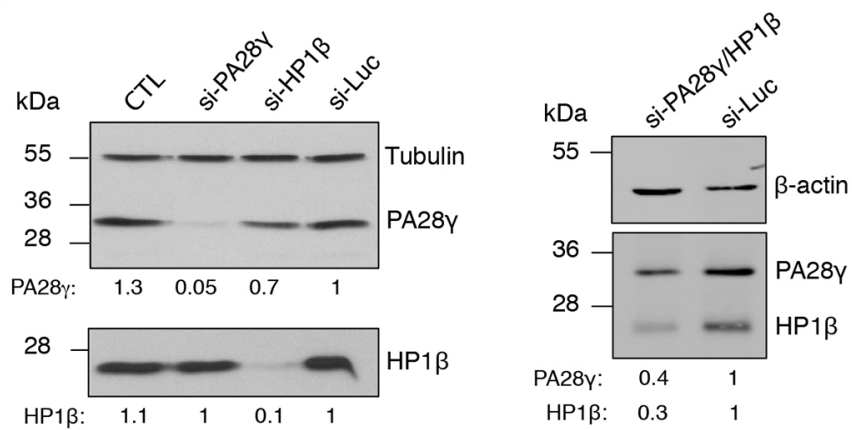

C
B

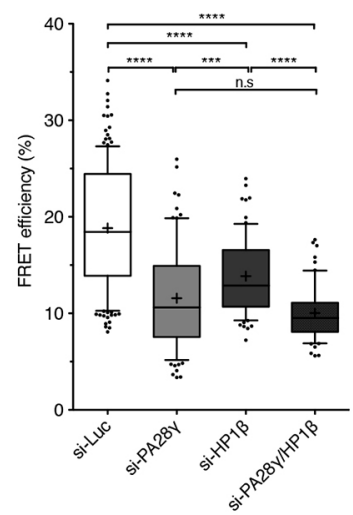

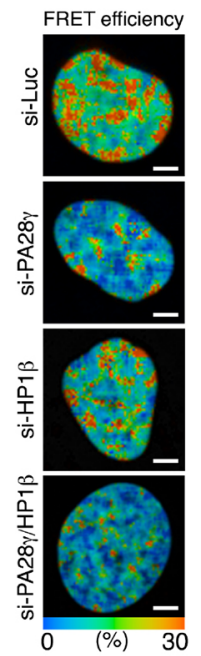

FRET \% distribution

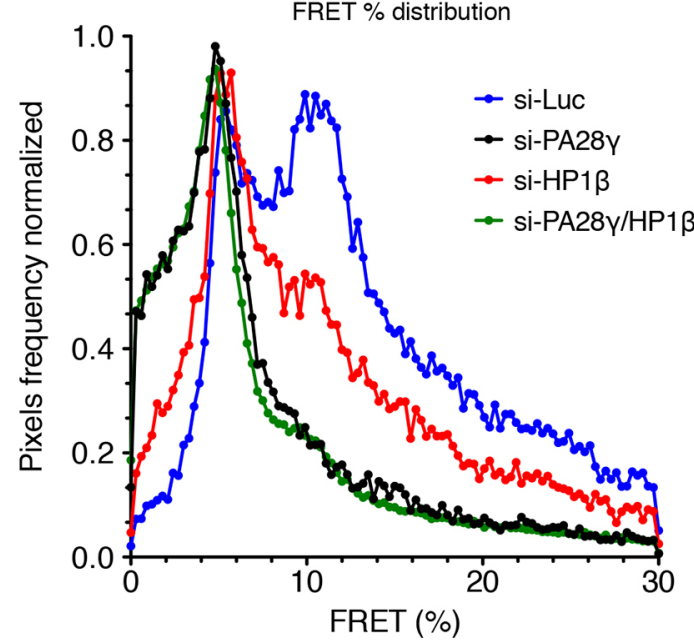

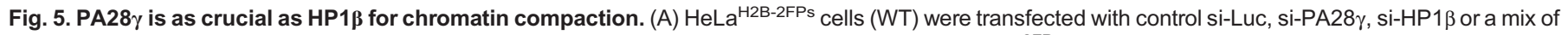
both siRNAs (si-PA28 $\gamma / \mathrm{HP} 1 \beta$ ) for $48 \mathrm{~h}$. Immunoblot analysis of PA28 $\gamma$ and HP1 $\beta$ protein levels in HeLa ${ }^{2 F P s}$ following siRNA treatments were performed.

Tubulin and anti- $\beta$ actin antibodies were used as loading controls. The relative abundance of PA28 $\gamma$ and HP1 $\beta$ proteins in the extracts was quantified using Image

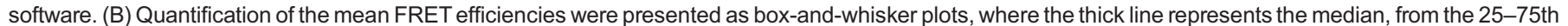
percentiles of the median, with the whiskers covering the 10th-90th percentile range. + indicates the mean FRET value. Data are from 4 independent

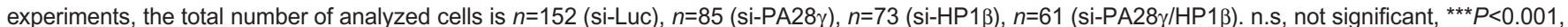
${ }^{* * *} P<0.0001$ (two-tailed unpaired Student's $t$-test). (C) Representative images of the spatial distribution of the FRET efficiency (percentage) in representative control si-Luc, si-PA28 $\gamma$, si-HP1 $\beta$ or both siRNAs (si-PA28 $\gamma / \mathrm{HP} 1 \beta$ ) treated HeLa ${ }^{\mathrm{H} 2 \mathrm{~B}-2 \mathrm{FPs}}$ nuclei is depicted in a continuous pseudocolor scale ranging from 0 to $30 \%$ (left panel). Scale bars: $10 \mu \mathrm{m}$. Mean FRET distribution graph showing distinct populations of FRET efficiency in si-Luc (blue curve), si-PA28 $\gamma$ (black), si-HP1 $\beta$ (red), or both si-PA28 $\gamma / \mathrm{HP} 1 \beta$ (green) treated HeLaH2B-2FPs (right panel).

pUC57-U6 (a gift from Dr E. Bertrand's laboratory, IGMM, Montpellier, France). For rescue experiments, PA28 $\gamma$ ORF WT or minus the C-terminal 14 amino acids $(\Delta \mathrm{C})$ were cloned into pSBbi-Pur (Addgene plasmid \#60523, deposited by Eric Kowarz) according to Kowarz et al. (2015). The resulting vector was co-transfected with pCMV(CAT)T7-SB100 (Addgene plasmid \#34879, deposited by Zsuzsanna Izsvak) into recipient cells, and puromycinresistant single colonies were selected for re-expression of PA28 $\gamma \mathrm{WT}$ or $\Delta \mathrm{C}$ proteins. pEGF-LacI (Jegou et al., 2009) was a generous gift from Prof. Karsten Rippe (DKFZ, Heidelberg, Germany).

\section{Antibodies}

The following antibodies were used at 1:1000 dilution, except where noted,

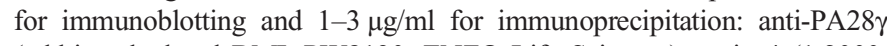
(rabbit polyclonal BML-PW8190, ENZO Life Sciences), anti- $\alpha 4$ (1:2000; mouse monoclonal BML-PW8120, ENZO Life Sciences); anti-PA28 $\gamma$ (mouse monoclonal, 611180, BD Transduction); anti-HP1 $\alpha$ (rabbit polyclonal, 2616S, Cell Signaling); anti-HP1 $\beta$ [rabbit monoclonal (D2F2), 8676S, Cell Signaling and mouse monoclonal (1MOD-1A9) 39979, Active Motif]; anti-GFP (mouse monoclonal, clone 7.1, 11814460001, Roche,
Sigma); anti-RFP (rat monoclonal, 5F8, Chromotek); anti- $\beta$-actin (rabbit monoclonal, 13E5, Cell Signaling); anti-H3K9me3 (mouse monoclonal, clone 2AG-6F12-H4, 39285, Active Motif); anti-H3K4me3 (mouse monoclonal, clone 2AG-6F12-H4, 39285, Active Motif); anti-histone H3 (rabbit polyclonal, ab1791, Abcam); anti-H4K20me1 (rabbit polyclonal, \#9724, Cell Signaling Technology); anti-H4K20me3 (rabbit monoclonal, \#5737, Cell Signaling Technology); anti-histone H1 (rabbit polyclonal, PA530055 , Thermo Fisher); and anti- $\alpha$-tubulin (mouse monoclonal, T9026, Sigma-Aldrich, 1:6000). Fluorescent secondary antibodies conjugated either to Alexa Fluor 488 or 594 (1:1000), or to DyLight 680 or $800(1: 10,000)$ were purchased from Thermo Fisher Scientific. Secondary antibodies conjugated to HRP were purchased from Bio-Rad SA (1:10,000).

\section{Cell culture, transfections, cell synchronization and FACS analysis}

U2OS (HTB-96) cells, obtained from ATCC, were grown in DMEM (Lonza) containing $4.5 \mathrm{~g} / \mathrm{l}$ glucose, $10 \%$ heat-inactivated fetal bovine serum (Biowest), $2 \mathrm{mM}$ glutamine, $100 \mathrm{U} / \mathrm{ml}$ penicillin and $10 \mu \mathrm{g} / \mathrm{ml}$ streptomycin (Lonza). U2OS-LacO (F42B8) cells (a generous gift of Prof. Karsten Rippe) 
A

H3K9me3

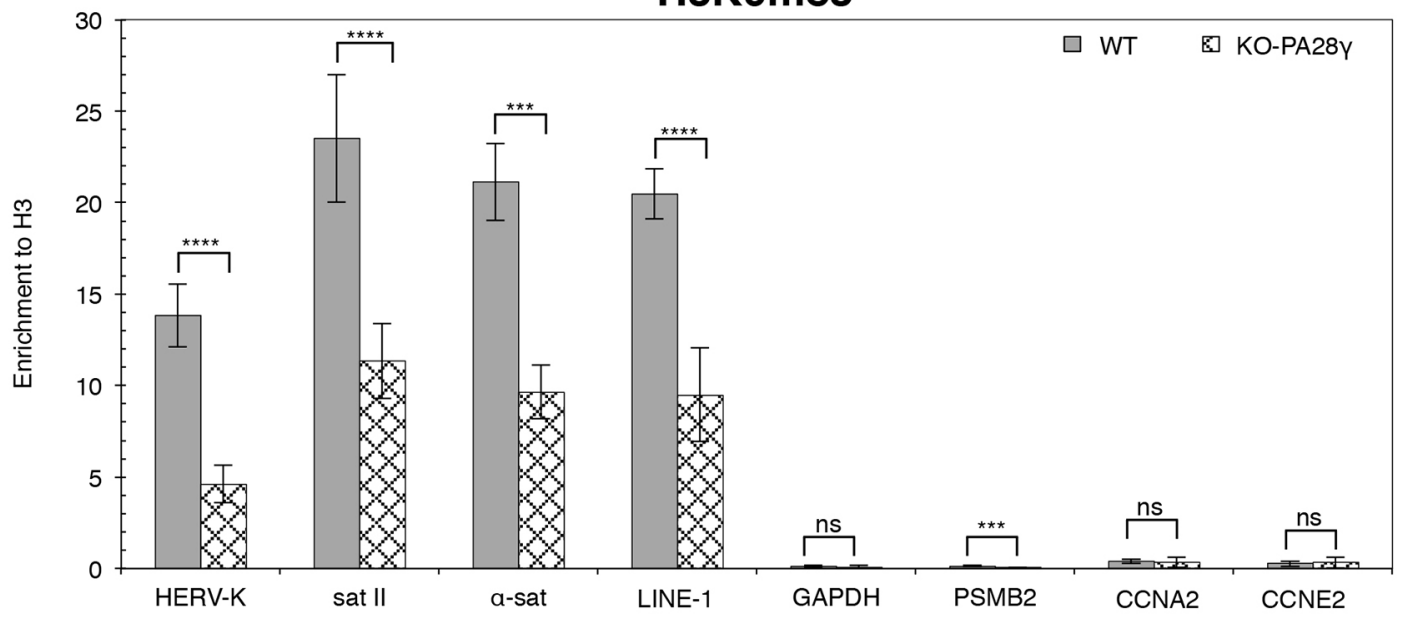

B

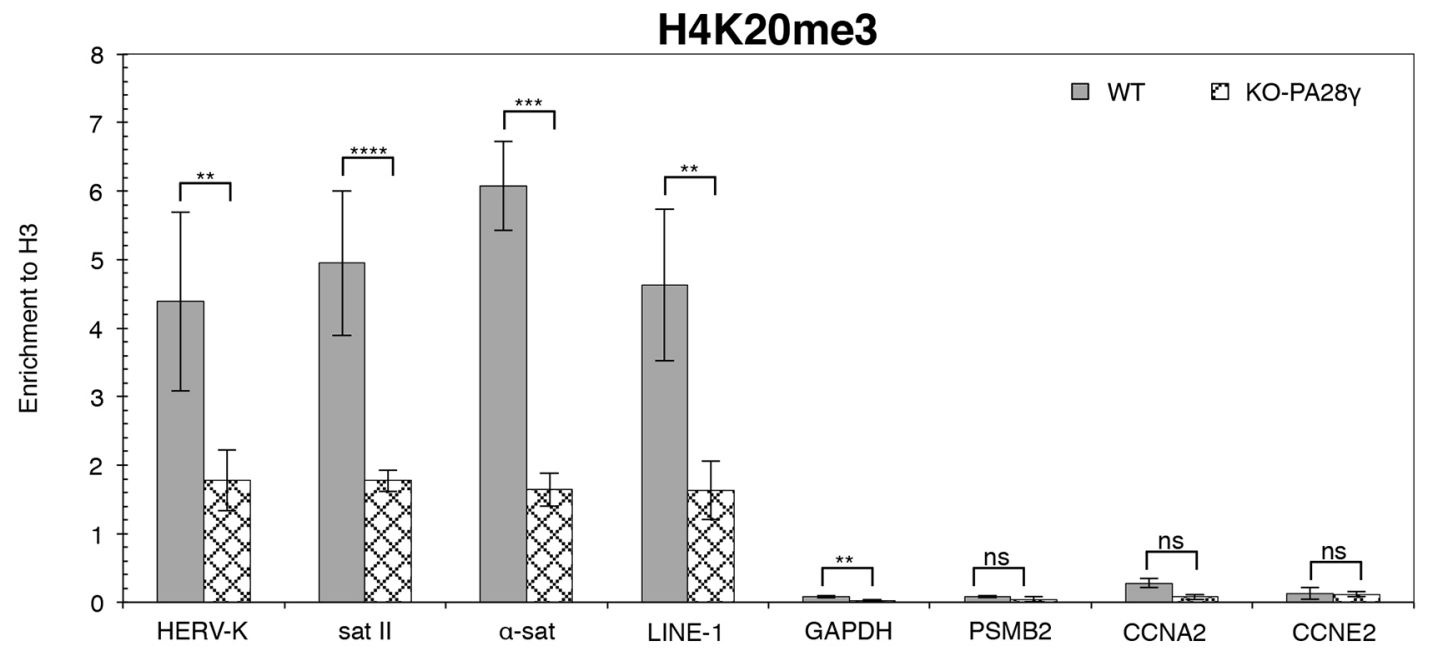

C
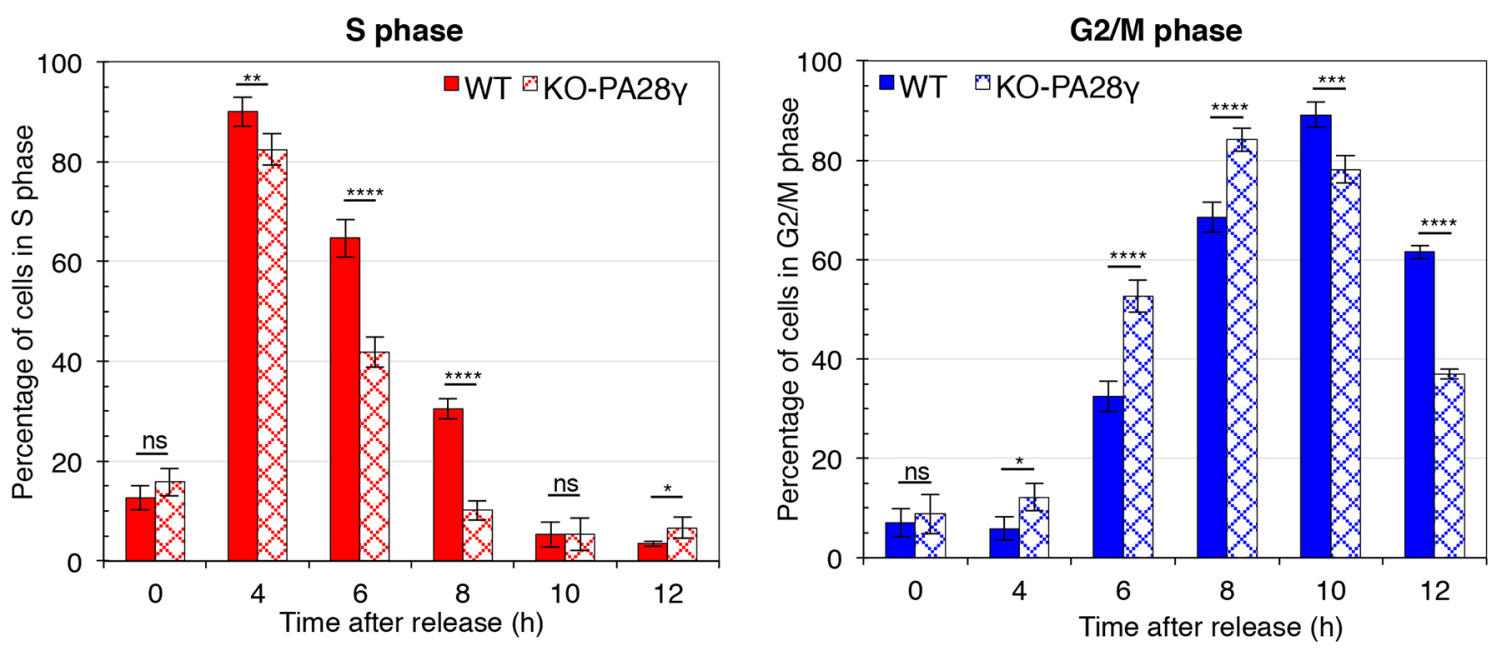

Fig. 6. See next page for legend.

were grown in the same medium as U2OS cells but containing G418 $(500 \mu \mathrm{g} / \mathrm{ml})$ (Jegou et al., 2009). Establishment and characterization of parental HeLa ${ }^{\text {H2B-GFP }}$ and HeLa ${ }^{\text {H2B-2FPs }}$ (H2B-GFP and mCherry-H2B) cell lines were previously described (Lleres et al., 2009). Of note, after thawing, cells were cultured for 1 week before seeding, for all experiments. All cell lines were tested for contamination. 
Fig. 6. PA28 $\gamma$ contributes to the maintenance of heterochromatin marks and PA28 $\gamma$ depletion decrease S-phase duration. (A,B) ChIP-qPCR analysis of $\mathrm{H} 3 \mathrm{~K} 9 \mathrm{me} 3(\mathrm{~A})$ and $\mathrm{H} 4 \mathrm{~K} 20 \mathrm{me} 3(\mathrm{~B})$ levels at different repetitive elements and gene promoters (as indicated on the $x$-axis) in WT versus KO-PA28 $\gamma$ U2OS cells. Data are represented as relative enrichments of each specific histone mark versus histone $\mathrm{H} 3$ control, as shown on the $y$-axis. Data are means \pm s.e.m. ( $n=5$ for H3K9me3 and histone H3, $n=3$ for H4K20me3). ns, not significant, ${ }^{* *} P<0.01,{ }^{* * *} P<0.001,{ }^{* * * *} P<0.0001$ (unpaired two-tailed Student's $t$-test; full $P$-values are presented in Table S1). (C) Asynchronous parental (WT) and KO-PA28 $\gamma$ U2OS cells (AS), cells synchronized at the G1/S phase transition by a double thymidine block $(0 \mathrm{~h})$ and released for the times indicated were subjected to FACS analysis. Histograms representing the percentage of the cells in S (left panel) and G2/M (right panel) phases of the cell cycle are shown. Data represent the means \pm s.d. from three biological repeats. ns, not significant, ${ }^{*} P<0.05,{ }^{* *} P<0.01,{ }^{* *} P<0.001,{ }^{* * *} P<0.0001$ (two-way ANOVA for each time point; full $P$-values are presented in Table S3).

For transient PA28 $\gamma$ and HP1 $\beta$ knockdown experiments, U2OS-LacO and/or HeLa (H2B-GFP or 2FPs) cells were transfected with $20 \mathrm{nM}$ Luciferase targeting siRNA (si-Luc, 5'-CGTACGCGGAATACTTCGA-3') used as negative control, or -PA28 $\gamma$ (PSME3), and -HP1 $\beta(C B X 1)$ targeting siRNA (si-PA28 $\gamma$ : 5'-GAAUCAAUAUGUCACUCUA-3'; si-HP1 $\beta$ : 5' AGGAAUAUGUGGUGGAAAA-3') purchased from Eurofins Genomics, using Lipofectamine RNAiMAX (Thermo Fisher Scientific) and examined after 2 days. Where indicated, cells were transiently transfected with $0.5 \mu \mathrm{g} /$ $\mathrm{ml}$ DNA using JetPEITM (Ozyme), according to the manufacturer's instructions and analyzed after 1 day. Stable U2OS (Jonik-Nowak et al., $2018), \mathrm{HeLa}^{\mathrm{H} 2 \mathrm{~B}-\mathrm{GFP}}$ - and $\mathrm{HeLa}^{2 \mathrm{FPs}}-\mathrm{KO}-\mathrm{PA} 28 \gamma$ cell lines were generated by co-transfection of PSME3/PA28 $\gamma$ sgGuide and pX459 vectors (Addgene plasmid \#62988, deposited by Feng Zhang), and cells were selected with puromycin $(1 \mu \mathrm{g} / \mathrm{ml})$. Single clones were then expanded and analyzed by western blotting using PA28 $\gamma$ antibodies. Synchronization of cells at the G1/ $\mathrm{S}$ phase transition was performed by double thymidine block as described previously (Thomas et al., 2014). For fluorescence-activated cell sorting (FACS) analysis, cells were fixed with $70 \%$ ethanol and conserved at $-20^{\circ} \mathrm{C}$. Before analysis, cells were washed with PBS, resuspended in PBS containing RNase A (1 mg/ml, Sigma-Aldrich) and propidium iodide (10 $\mathrm{g} / \mathrm{ml}$, Sigma-Aldrich) and incubated for $30 \mathrm{~min}$ at room temperature.
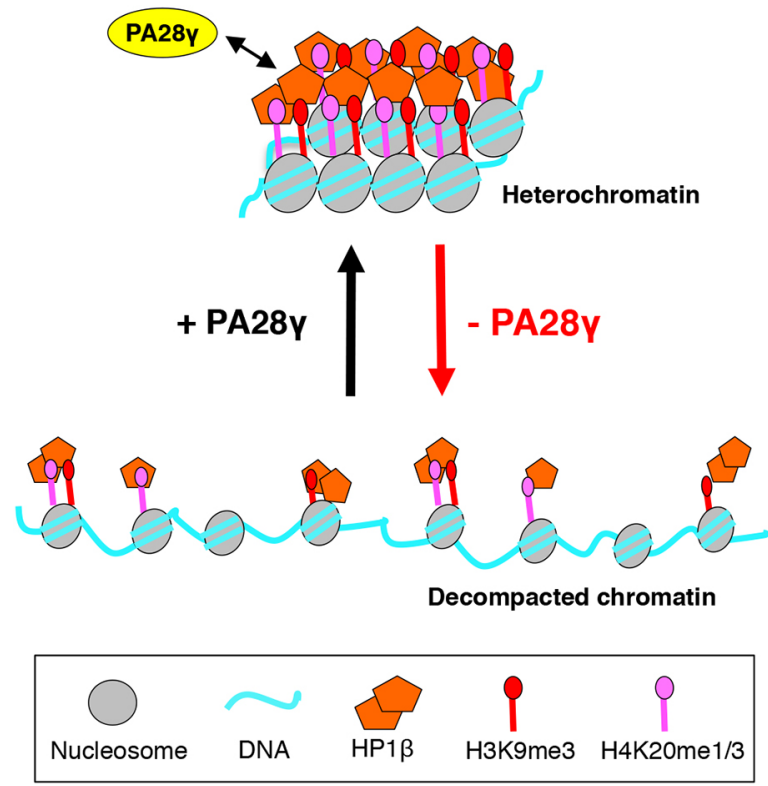

Fig. 7. Schematic summary of findings. Our results show that PA28 $\gamma$, as $\mathrm{HP} 1 \beta$, is associated with heterochromatin domains. In the absence of PA28 $\gamma$, the tri-methylation level of $\mathrm{H} 3 \mathrm{~K} 9$ and $\mathrm{H} 4 \mathrm{~K} 20$ is substantially reduced, as a consequence preventing the compaction of these heterochromatin domains, even in the presence of HP1 $\beta$.
Samples were run on a FACSCalibur Cell Analyzer (Becton-Dickinson), and data analysis was performed using CellQuest Pro software (BectonDickinson).

\section{Immunofluorescence and is-PLA assays}

Cells on coverslips were fixed in $3.7 \%$ paraformaldehyde in PBS at room temperature, then permeabilized with $0.25 \%$ Triton X-100 in PBS for $5 \mathrm{~min}$, followed by incubation in methanol $(100 \%)$ at $-20^{\circ} \mathrm{C}$ for $10 \mathrm{~min}$. After washes with PBS, cells were blocked with $1 \%$ calf serum in PBS for $15 \mathrm{~min}$. Incubation with primary antibodies [anti-PA28 1:6000 for BML-PW8190 or $1: 1000$ for 611180); anti- $\alpha 4$ (1:4000 BML-PW8120); anti-HP1 $\alpha$ (1:800, $2616 \mathrm{~S})$; anti-HP1 $\beta$ (1:1000 8676S and 1MOD-1A9)] was carried out at $37^{\circ} \mathrm{C}$ for $1 \mathrm{~h}$ in a humidified atmosphere. After washes, cells were incubated with Alexa Fluor-conjugated secondary antibodies for $40 \mathrm{~min}$ at room temperature (RT). DNA was stained with $0.1 \mu \mathrm{g} / \mathrm{ml}$ DAPI (Sigma-Aldrich) solution $5 \mathrm{~min}$ at RT, cells were washed twice in PBS and finally once in $\mathrm{H}_{2} \mathrm{O}$. Coverslips were mounted on glass slides using ProLong Gold anti-fade reagent (Thermo Fisher Scientific). For in situ proximity ligation assays (is-PLA), cells on coverslips were fixed and permeabilized as above. Coverslips were then blocked in a solution provided by the Duolink ${ }^{\circledR}$ kit (Sigma-Aldrich). Cells were then incubated with antibodies as described above. Duolink ${ }^{\circledR}$ In Situ PLA Probe Anti-Rabbit MINUS and Anti-Mouse PLUS and Duolink ${ }^{\circledR}$ In Situ Detection Reagents (Sigma-Aldrich) were used, according to the manufacturer's instructions. In some specific experiments, cells were permeabilized prior to fixation with $0.5 \%$ Triton $\mathrm{X}-100$ in PBS for $5 \mathrm{~min}$ at $4{ }^{\circ} \mathrm{C}$ for the colocalization between endogenous PA28 $\gamma$ and HP1 $\beta$ in U2OS cells.

$2 \mathrm{D}$ and $Z$-stack images were acquired with $63 \times / 1.32 \mathrm{NA}$ or $100 \times / 1.4 \mathrm{NA}$ oil immersion objective lenses using a DM 6000 microscope (Leica). Microphotographs were taken with a 12-bit CoolSNAP HQ2 camera. Images were acquired as TIFF files using MetaMorph imaging software (Molecular Devices). For quantitative analyses of PLA dots, $Z$-stacks were acquired every $0.3 \mu \mathrm{m}$ ( $Z$ step) with a range of 6-7.5 $\mu \mathrm{m}$. For endogenous detection, images (as a $Z$ stack, slices every $200 \mathrm{~nm}$ ) were also acquired on a Zeiss LSM 880 point scanning confocal microscope equipped with a $63 \times$ Plan-Apochromat 1.4NA oil immersion objective (Zeiss) and using the $488 \mathrm{~nm}$ and $561 \mathrm{~nm}$ laser lines with the Airyscan detector. The Zeiss Zen black software was used to process the Airyscan raw images. Colocalization in 3D, between PA28 $\gamma$ and HP1 $\beta$, was analyzed using the Imaris (Bitplane) colocalization module.

The number of PLA dots and the size of GFP-LacI dots were determined using ImageJ $(1.49 \mathrm{v})$. Custom macros (available upon request) were created to automatically quantify these different parameters. The script allows the creation of a mask of DAPI image to isolate the nucleus of each cell and create a maximum intensity projection (MIP) of the Z-stacks or the image. The mask is used in the MIP to count the number of PLA-dots of each nucleus via an appropriate threshold. The 'Analyze Particles' tool of ImageJ was used to calculate the size of each GFP-LacI dot

\section{FLIM-FRET microscopy}

FLIM-FRET data were acquired with a Zeiss LSM 780 laser scanning microscope coupled to a 2-photon Ti:Sapphire laser (Chameleon Ultra II tunable 680-1080 nm, Coherent) producing 150-femtosecond pulses at $80 \mathrm{MHz}$ repetition rate and a time correlated single photon counting (TCSPC) electronics (SPC-830; Becker \& Hickl GmbH) for time-resolved detection. Enhanced green fluorescent protein (EGFP) and mCherry fluorophores were used as a FRET pair. The two-photon excitation laser was tuned to $890 \mathrm{~nm}$ for selective excitation of the donor fluorophore. The LSM780 microscope is equipped with a temperature- and $\mathrm{CO}_{2}$-controlled environmental black wall chamber. Measurements were acquired in live cells at $37^{\circ} \mathrm{C}, 5 \% \mathrm{CO}_{2}$ with a $63 \times / 1.4$ oil Plan-Apochromat objective lens. A short-pass 760-nm dichroic mirror was used to separate the fluorescence signal from the laser light. Enhanced detection of the emitted photons was afforded by the use of the HPM-100 module (Hamamatsu R10467-40 GaAsP hybrid PMT tube). The FLIM data were processed using SPCimage software (Becker \& Hickl GmbH).

\section{FLIM-FRET analysis}

FLIM-FRET experiments were performed in HeLa cells stably expressing $\mathrm{H} 2 \mathrm{~B}-\mathrm{GFP}$ alone $\left(\mathrm{HeLa}^{\mathrm{H} 2 \mathrm{~B}-\mathrm{GFP}}\right)$ or with mCherry-tagged histone $\mathrm{H} 2 \mathrm{~B}$ 
$\left(\mathrm{HeLa}^{\mathrm{H} 2 \mathrm{~B}-2 \mathrm{FPs}}\right) .5 \times 10^{4}$ cells were seeded in a FluoroDish 35 (FD35-100, World Precision Instruments). For siRNA experiments, $24 \mathrm{~h}$ after seeding, cells were transfected with $20 \mathrm{nM}$ of siRNA (against Luciferase, PA28 $\gamma$ or HP1 $\beta$ ) and FLIM-FRET experiments were performed $48 \mathrm{~h}$ later. At $30 \mathrm{~min}$ prior to imaging, the culture medium was changed to complete DMEM without Phenol Red. An acquisition time of $90 \mathrm{~s}$ was set up for each FLIM experiment. The analysis of the FLIM measurements was performed by using SPCImage software (Becker \& Hickl, GmbH). Because FRET interactions cause a decrease in the fluorescence lifetime of the donor molecules (EGFP), the FRET efficiency was calculated by comparing the FLIM values obtained for the EGFP donor fluorophores in the presence $\left(\mathrm{HeLa}^{\text {H2B-2FP }}\right)$ and absence (HeLa ${ }^{\text {H2B-GFP }}$ ) of the mCherry acceptor fluorophores. FRET efficiency ( $E$ FRET) was derived by applying the following equation: $E$ FRET $=1-(\tau \mathrm{DA} / \tau \mathrm{D})$ at each pixel in a selected region of interest (nucleus) using SPCImage software. $\tau \mathrm{DA}$ is the mean fluorescence lifetime of the donor (H2B-EGFP) in the presence of the acceptor mCherry-H2B in HeLa ${ }^{\text {H2B-2PPs }}$ cells and $\tau \mathrm{D}$ is the mean fluorescence lifetime of H2B-EGFP (in the absence of acceptor) in HeLa ${ }^{\text {H2B-GiPP }}$ cells. The FRET distribution curves from nuclei were displayed from the extracted associated matrix using SPCImage and then normalized and graphically represented using Microsoft Excel and GraphPad Prism software. For each experiment, FLIM was performed on multiple cells from several independent experiments (see figure legends).

\section{Immunoprecipitation and immunoblotting}

For immunoprecipitation, cells were lysed in lysis buffer $[50 \mathrm{mM}$ Tris- $\mathrm{HCl}$, $\mathrm{pH} 7.5,150 \mathrm{mM} \mathrm{NaCl}, 5 \mathrm{mM} \mathrm{MgCl} 2,1 \%$ IGEPAL CA-630, $0.5 \%$ sodium deoxycholate (DOC), $0.1 \%$ SDS, $1 \mathrm{mM}$ DTT, $5 \mathrm{mM}$ EDTA, $50 \mathrm{mM} \mathrm{NaF}$ and $\left.1 \mathrm{mM} \mathrm{Na}_{3} \mathrm{VO}_{4}\right]$ in the presence of complete EDTA-free protease inhibitor cocktail (Roche Life Science) for $20 \mathrm{~min}$ at $4^{\circ} \mathrm{C}$. Lysates were clarified by centrifugation for $10 \mathrm{~min}$ at $10,000 \mathrm{~g}$ and the protein concentration of the supernatant was determined using BSA as a standard (CooAssay protein dosage reagent, Interchim). Total lysate (200 $\mu \mathrm{g})$ was pre-cleared for $30 \mathrm{~min}$, and immunoprecipitations were performed using the antibodies indicated and protein A magnetic beads (Dynal, Lake Success, $\mathrm{NY}$ ) for $2 \mathrm{~h}$ at $4^{\circ} \mathrm{C}$ with constant gentle stirring. After several washes, bead pellets were boiled in $2 \times$ Laemmli buffer, separated by SDS-PAGE, and subjected to immunoblotting.

\section{ChIP-qPCR}

ChIP experiments with U2OS cells were performed as described previously (Brustel et al., 2017). Briefly, cells were fixed with $1 \%$ formaldehyde (10 min) and quenching was performed with $125 \mathrm{mM}$ glycine. After a PBS wash, cells were resuspended in buffer A (10 mM Tris- $\mathrm{HCl} \mathrm{pH} 8,10 \mathrm{mM}$ $\mathrm{KCl}, 0.25 \%$ Triton X-100, $1 \mathrm{mM}$ EDTA, $0.5 \mathrm{mM}$ EGTA) for $5 \mathrm{~min}$ on ice. After centrifugation, nuclei were extracted with buffer B $(10 \mathrm{mM}$ Tris-HCl $\mathrm{pH}$ 8, $200 \mathrm{mM} \mathrm{NaCl}, 1 \mathrm{mM}$ EDTA, $0.5 \mathrm{mM}$ EGTA) for $10 \mathrm{~min}$ on ice. To extract chromatin, nuclei were resuspended in lysis buffer $(10 \mathrm{mM}$ Tris- $\mathrm{HCl}$ $\mathrm{pH} 8,140 \mathrm{mM} \mathrm{NaCl}, 0.1 \%$ SDS, $0.5 \%$ Triton X-100, 0.05\% DOC, $1 \mathrm{mM}$ EDTA, $0.5 \mathrm{mM}$ EGTA). After sonication with an EpiShear probe sonicator (Active Motif) to obtain chromatin fragments less than $800 \mathrm{bp}$, ChIP was performed with $15-30 \mu \mathrm{g}$ of sheared chromatin incubated with protein A magnetic beads (Invitrogen, Thermo Fisher Scientific) coupled with the appropriate antibody, as follows: anti-H3pan $(1 \mu \mathrm{l} / \mathrm{ChIP}, \mathrm{C} 15310135$, Diagenode), anti-H3K9me3 ( $2 \mu \mathrm{l} / \mathrm{ChIP}, \mathrm{C} 15410056$, Diagenode), antiH3K4me3 (1 $\mu \mathrm{l} / \mathrm{ChIP}, \mathrm{C} 15410003$, Diagenode) anti-H4K20me3 (2 $\mu \mathrm{l} /$ ChIP, C15410207, Diagenode), anti-PA28 $\gamma$ (0.5 $\mu$ /ChIP, ENZO Life Sciences), and anti-HP1 $\beta$ [2 $\mu \mathrm{l} / \mathrm{ChIP}$, rabbit monoclonal (D2F2), 8676S, Cell Signaling]. ChIP experiments were performed at least three times from independent chromatin preparations and quantitative PCR analyses of ChIP DNAs were performed using a SYBR green quantitative PCR kit (Invitrogen, Thermo Fisher Scientific) and a LightCycler $480 \mathrm{II}$ instrument (Roche) under conditions standardized for each primer set. The amount of DNA in ChIP samples was extrapolated from standard curve analysis of chromatin DNA before immunoprecipitation (input), and values were represented as the ratio between the percentage of input obtained for each antibody to the ones obtained for histone H3. Primer sets used for qPCR were: HERV-K For, 5'-TGCCAAACCTGAGGAAGAAGGGAT-3' and HERV-K Rev, 5'-TGCAGGC ATTAAACATCCTGGTGC-3'; Sat-II
For, 5'-CCAGAAGGTAATAAGTGGCACAG-3' and Sat-II Rev, 5'-CCCTCCTTGAGCATTCTAACTACC-3'; $\alpha$-Sat For, 5'-GAAACACTCTTTCTGCACTACCTG- $3^{\prime}$ and $\alpha$-Sat Rev, $5^{\prime}$-GGATGGTTCAACACTCTTACATGA-3' (Djeghloul et al., 2016); LINE-1 5'UTR For, 5'CAGCTTTGAAGAGAGCAGTGG-3' and LINE-1 5'UTR Rev, 5'-GTCAGGGACCCACTTGAGG-3' (Filipponi et al., 2013); CCNA2 For, 5'-ACTAGACGTCCCAGAGCTAAA-3' and CCNA2 Rev, 5'-TGTCCGAAGGCTGACTCTAA-3'; CCNE2 For; 5'-AAGCGTTAGAAATGGCAGAAAG-3' and CCNE2 Rev, 5'-TCTCTCCCTAATTTACCTGTAGGA3'; GAPDH For, 5'-GCACGTAGCTCAGGCCTCAAGAC-3' and GAPDH Rev, 5'-GACTGTCGAACAGGAGGAGCAGAG-3'; and PSMB2 For, 5'-GTGCTTGTCTCTGGGATCGT-3' and PSMB2 Rev, 5'-AAACTGGGCGTCACATAAGG-3' (https://www.chipprimers.com/).

\section{Statistics}

Error bars represent standard deviations unless otherwise noted. Different tests were used to determine significance, and as noted in the legend. Differences were considered significant when $P<0.05$ and are indicated by different numbers of asterisks, as follows: $* P<0.05 ; \quad * * P<0.01$; $* * * P<0.001$; and $* * * * P<0.001$.

\section{Acknowledgements}

We thank K. Rippe (DKFZ, Heidelberg, Germany) for providing U2OS-LacO (F42B8) cell and the pEGFP-Lacl vector, P. Fort for help with statistical analysis, N. Morin for help with Airyscan microscopy, E. Julien for useful scientific discussions and advice and R. Feil for advice; and the Montpellier Ressources Imagerie (MRI) platform, a member of the National Infrastructure France-Biolmaging supported by the French National Agency (ANR-10-INSB-04, Investments for the Future). We thank J. Hutchins for checking the scientific English.

\section{Competing interests}

The authors declare no competing or financial interests.

\section{Author contributions}

Conceptualization: V.B.; Methodology: D.F., D.L., C.G., C.V., C.B.-A., V.B.; Validation: D.F., D.L., C.G., C.B.-A., V.B.; Formal analysis: D.F., D.L., C.G., O.C., C.B.-A., V.B.; Investigation: D.F., D.L., C.G., C.V., F.M., S.B., C.B.-A., V.B.; Writing original draft: C.B.-A., V.B.; Supervision: V.B.; Project administration: V.B.; Funding acquisition: D.L., S.B., O.C., V.B.

\section{Funding}

Institutional support was provided by the Centre National de la Recherche Scientifique (CNRS) and the University of Montpellier. This work was also supported by grants from the People Programme (Marie Curie Actions) of the EU Seventh Framework Programme (FP7 REA agreement 290257, UPStream, to O.C.), Comité de l'Aude et Comité du Gard de la Ligue Nationale Contre le Cancer (2014 and 372015, to V.B.), Fondation ARC pour la Recherche sur le Cancer (SFI20111203984, to S.B. and PJA20181207962, to D.L.).

\section{Supplementary information}

Supplementary information available online at

https://jcs.biologists.org/lookup/doi/10.1242/jcs.257717.supplemental

\section{References}

Alpsoy, A. and Dykhuizen, E. C. (2018). Glioma tumor suppressor candidate region gene 1 (GLTSCR1) and its paralog GLTSCR1-like form SWI/SNF chromatin remodeling subcomplexes. J. Biol. Chem. 293, 3892-3903. doi:10. 1074/jbc.RA117.001065

Ayarpadikannan, S. and Kim, H.-S. (2014). The impact of transposable elements in genome evolution and genetic instability and their implications in various diseases. Genomics Inform. 12, 98-104. doi:10.5808/GI.2014.12.3.98

Baldin, V., Militello, M., Thomas, Y., Doucet, C., Fic, W., Boireau, S., JarielEncontre, I., Piechaczyk, M., Bertrand, E., Tazi, J. et al. (2008). A novel role for PA28 $\gamma$-proteasome in nuclear speckle organization and SR protein trafficking. Mol. Biol. Cell 19, 1706-1716. doi:10.1091/mbc.e07-07-0637

Barton, L. F., Runnels, H. A., Schell, T. D., Cho, Y., Gibbons, R., Tevethia, S. S., Deepe, G. S., Jr. and Monaco, J. J. (2004). Immune defects in $28-\mathrm{kDa}$ proteasome activator $\gamma$-deficient mice. J. Immunol. 172, 3948-3954. doi:10.4049/ jimmunol.172.6.3948

Beck, D. B., Oda, H., Shen, S. S. and Reinberg, D. (2012). PR-Set7 and H4K20me1: at the crossroads of genome integrity, cell cycle, chromosome condensation, and transcription. Genes Dev. 26, 325-337. doi:10.1101/gad. 177444.111 
Bosch-Presegué, L., Raurell-Vila, H., Thackray, J. K., González, J., Casal, C. Kane-Goldsmith, N., Vizoso, M., Brown, J. P., Gómez, A., Ausió, J. et al. (2017). Mammalian HP1 isoforms have specific roles in heterochromatin structure and organization. Cell Rep. 21, 2048-2057. doi:10.1016/j.celrep.2017.10.092

Brustel, J., Kirstein, N., Izard, F., Grimaud, C., Prorok, P., Cayrou, C., Schotta G., Abdelsamie, A. F., Déjardin, J., Méchali, M. et al. (2017). Histone H4K20 trimethylation at late-firing origins ensures timely heterochromatin replication. EMBO J. 36, 2726-2741. doi:10.15252/embj.201796541

Chen, X., Barton, L. F., Chi, Y., Clurman, B. E. and Roberts, J. M. (2007) Ubiquitin-independent degradation of cell-cycle inhibitors by the REG proteasome. Mol. Cell 26, 843-852. doi:10.1016/j.molcel.2007.05.022

Cioce, M., Boulon, S., Matera, A. G. and Lamond, A. I. (2006). UV-induced fragmentation of Cajal bodies. J. Cell Biol. 175, 401-413. doi:10.1083/jcb. 200604099

Collins, G. A. and Goldberg, A. L. (2017). The logic of the 26 S proteasome. Cell 169, 792-806. doi:10.1016/j.cell.2017.04.023

Coux, O., Zieba, B. A. and Meiners, S. (2020). The proteasome system in health and disease. Adv. Exp. Med. Biol. 1233, 55-100. doi:10.1007/978-3-030-38266-7 3

Dambacher, S., Hahn, M. and Schotta, G. (2013). The compact view on heterochromatin. Cell Cycle 12, 2925-2926. doi:10.4161/cc.26179

Djeghloul, D., Kuranda, K., Kuzniak, I., Barbieri, D., Naguibneva, I., Choisy, C., Bories, J.-C., Dosquet, C., Pla, M., Vanneaux, V. et al. (2016). Age-associated decrease of the histone methyltransferase SUV39H1 in HSC perturbs heterochromatin and B lymphoid differentiation. Stem Cell Rep. 6, 970-984. doi:10.1016/j.stemcr.2016.05.007

Erdel, F. and Rippe, K. (2018). Formation of chromatin subcompartments by phase separation. Biophys. J. 114, 2262-2270. doi:10.1016/j.bpj.2018.03.011

Erdel, F., Rademacher, A., Vlijm, R., Tünnermann, J., Frank, L., Weinmann, R. Schweigert, E., Yserentant, K., Hummert, J., Bauer, C. et al. (2020). Mouse heterochromatin adopts digital compaction states without showing hallmarks of HP1-driven liquid-liquid phase separation. Mol. Cell 78, 236-249.e7. doi:10.1016/ j.molcel.2020.02.005

Fabre, B., Lambour, T., Garrigues, L., Ducoux-Petit, M., Amalric, F., Monsarrat, B., Burlet-Schiltz, O. and Bousquet-Dubouch, M.-P. (2014). Label-free quantitative proteomics reveals the dynamics of proteasome complexes composition and stoichiometry in a wide range of human cell lines. J. Proteome Res. 13, 3027-3037. doi:10.1021/pr500193k

Filipponi, D., Muller, J., Emelyanov, A. and Bulavin, D. V. (2013). Wip1 controls global heterochromatin silencing via ATM/BRCA1-dependent DNA methylation. Cancer Cell 24, 528-541. doi:10.1016/j.ccr.2013.08.022

Förster, A., Masters, E. I., Whitby, F. G., Robinson, H. and Hill, C. P. (2005). The $1.9 \AA$ structure of a proteasome-11S activator complex and implications for proteasome-PAN/PA700 interactions. Mol. Cell 18, 589-599. doi:10.1016/j. molcel.2005.04.016

Geng, F. and Tansey, W. P. (2012). Similar temporal and spatial recruitment of native 19S and 20S proteasome subunits to transcriptionally active chromatin. Proc. Natl. Acad. Sci. USA 109, 6060-6065. doi:10.1073/pnas.1200854109

Grewal, S. I. S. and Jia, S. (2007). Heterochromatin revisited. Nat. Rev. Genet. 8 35-46. doi:10.1038/nrg2008

Guillot, P. V., Xie, S. Q., Hollinshead, M. and Pombo, A. (2004). Fixation-induced redistribution of hyperphosphorylated RNA polymerase II in the nucleus of human cells. Exp. Cell Res. 295, 460-468. doi:10.1016/j.yexcr.2004.01.020

Howe, F. S., Fischl, H., Murray, S. C. and Mellor, J. (2017). Is H3K4me3 instructive for transcription activation? BioEssays 39, e201600095. doi:10.1002/bies 201600095

Janssen, A., Colmenares, S. U. and Karpen, G. H. (2018). Heterochromatin guardian of the genome. Annu. Rev. Cell Dev. Biol. 34, 265-288. doi:10.1146/ annurev-cellbio-100617-062653

Jegou, T., Chung, I., Heuvelman, G., Wachsmuth, M., Görisch, S. M., GreulichBode, K. M., Boukamp, P., Lichter, P. and Rippe, K. (2009). Dynamics of telomeres and promyelocytic leukemia nuclear bodies in a telomerase-negative human cell line. Mol. Biol. Cell 20, 2070-2082. doi:10.1091/mbc.e08-02-0108

Jonik-Nowak, B., Menneteau, T., Fesquet, D., Baldin, V., Bonne-Andrea, C., Méchali, F., Fabre, B., Boisguerin, P., de Rossi, S., Henriquet, C. et al. (2018) PIP30/FAM192A is a novel regulator of the nuclear proteasome activator PA28 Proc. Natl. Acad. Sci. USA 115, E6477-E6486. doi:10.1073/pnas.1722299115

Kito, Y., Matsumoto, M., Hatano, A., Takami, T., Oshikawa, K., Matsumoto, A. and Nakayama, K. I. (2020). Cell cycle-dependent localization of the proteasome to chromatin. Sci. Rep. 10, 5801. doi:10.1038/s41598-020-62697-2

Klement, K. and Goodarzi, A. A. (2014). DNA double strand break responses and chromatin alterations within the aging cell. Exp. Cell Res. 329, 42-52. doi:10.1016/ j.yexcr.2014.09.003

Kowarz, E., Löscher, D. and Marschalek, R. (2015). Optimized Sleeping Beauty transposons rapidly generate stable transgenic cell lines. Biotechnol. J. 10 647-653. doi:10.1002/biot.201400821

Kumar, A. and Kono, H. (2020). Heterochromatin protein 1 (HP1): interactions with itself and chromatin components. Biophys. Rev. 12, 387-400. doi:10.1007/ s12551-020-00663-y
Lachner, M., O'Carroll, D., Rea, S., Mechtler, K. and Jenuwein, T. (2001) Methylation of histone H3 lysine 9 creates a binding site for HP1 proteins. Nature 410, 116-120. doi:10.1038/35065132

Larson, A. G., Elnatan, D., Keenen, M. M., Trnka, M. J., Johnston, J. B., Burlingame, A. L., Agard, D. A., Redding, S. and Narlikar, G. J. (2017). Liquid droplet formation by $\operatorname{HP} 1 \alpha$ suggests a role for phase separation in heterochromatin. Nature 547, 236-240. doi:10.1038/nature22822

Levy-Barda, A., Lerenthal, Y., Davis, A. J., Chung, Y. M., Essers, J., Shao, Z., van Vliet, N., Chen, D. J., Hu, M. C.-T., Kanaar, R. et al. (2011). Involvement of the nuclear proteasome activator PA28 $\gamma$ in the cellular response to DNA doublestrand breaks. Cell Cycle 10, 4300-4310. doi:10.4161/cc.10.24.18642

Li, X., Lonard, D. M., Jung, S. Y., Malovannaya, A., Feng, Q., Qin, J., Tsai, S. Y., Tsai, M.-J. and O'Malley, B. W. (2006). The SRC-3/AIB1 coactivator is degraded in a ubiquitin- and ATP-independent manner by the REG $\gamma$ proteasome. Cell 124 381-392. doi:10.1016/j.cell.2005.11.037

Li, X., Amazit, L., Long, W., Lonard, D. M., Monaco, J. J. and O'Malley, B. W. (2007). Ubiquitin- and ATP-independent proteolytic turnover of p21 by the REG $\gamma$ proteasome pathway. Mol. Cell 26, 831-842. doi:10.1016/j.molcel.2007.05.028

Li, S., Jiang, C., Pan, J., Wang, X., Jin, J., Zhao, L., Pan, W., Liao, G., Cai, X., Li, X. et al. (2015). Regulation of C-Myc protein stability by proteasome activator REGgamma. Cell Death Differ. 22, 1000-1011. doi:10.1038/cdd.2014.188

Lippman, Z., Gendrel, A.-V., Black, M., Vaughn, M. W., Dedhia, N., McCombie, W. R., Lavine, K., Mittal, V., May, B., Kasschau, K. D. et al. (2004). Role of transposable elements in heterochromatin and epigenetic control. Nature 430 471-476. doi:10.1038/nature02651

Liu, Y., Qin, S., Lei, M., Tempel, W., Zhang, Y., Loppnau, P., Li, Y. and Min, J. (2017). Peptide recognition by heterochromatin protein 1 (HP1) chromoshadow domains revisited: Plasticity in the pseudosymmetric histone binding site of human HP1. J. Biol. Chem. 292, 5655-5664. doi:10.1074/jbc.M116.768374

Lleres, D., James, J., Swift, S., Norman, D. G. and Lamond, A. I. (2009). Quantitative analysis of chromatin compaction in living cells using FLIM-FRET. J. Cell Biol. 187, 481-496. doi:10.1083/jcb.200907029

Ma, C. P., Slaughter, C. A and DeMartino, G. N. (1992). Identification, purification, and characterization of a protein activator (PA28) of the $20 \mathrm{~S}$ proteasome (macropain). J. Biol. Chem. 267, 10515-10523. doi:10.1016/S00219258(19)50047-3

Ma, C. P., Willy, P. J., Slaughter, C. A. and DeMartino, G. N. (1993). PA28, an activator of the $20 \mathrm{~S}$ proteasome, is inactivated by proteolytic modification at its carboxyl terminus. J. Biol. Chem. 268, 22514-22519. doi:10.1016/S0021 9258(18)41559-1

Machida, S., Takizawa, Y., Ishimaru, M., Sugita, Y., Sekine, S., Nakayama, J.-I., Wolf, M. and Kurumizaka, H. (2018). Structural basis of heterochromatin formation by human HP1. Mol. Cell 69, 385-397.e388. doi:10.1016/j.molcel.2017. 12.011

Maison, C. and Almouzni, G. (2004). HP1 and the dynamics of heterochromatin maintenance. Nat. Rev. Mol. Cell Biol. 5, 296-305. doi:10.1038/nrm1355

Mao, I., Liu, J., Li, X. and Luo, H. (2008). REG $\gamma$, a proteasome activator and beyond? Cell. Mol. Life Sci. 65, 3971-3980. doi:10.1007/s00018-008-8291-z

Martin, C. and Zhang, Y. (2005). The diverse functions of histone lysine methylation. Nat. Rev. Mol. Cell Biol. 6, 838-849. doi:10.1038/nrm1761

Masson, P., Lundgren, J. and Young, P. (2003). Drosophila proteasome regulator REG $\gamma$ : transcriptional activation by DNA replication-related factor DREF and evidence for a role in cell cycle progression. J. Mol. Biol. 327, 1001-1012. doi:10. 1016/S0022-2836(03)00188-8

McCann, T. S. and Tansey, W. P. (2014). Functions of the proteasome on chromatin. Biomolecules 4, 1026-1044. doi:10.3390/biom4041026

Murata, S., Kawahara, H., Tohma, S., Yamamoto, K., Kasahara, M., Nabeshima Y.-I., Tanaka, K. and Chiba, T. (1999). Growth retardation in mice lacking the proteasome activator PA28gamma. J. Biol. Chem. 274, 38211-38215. doi:10. 1074/jbc.274.53.38211

Nishibuchi, G. and Nakayama, J.-I. (2014). Biochemical and structural properties of heterochromatin protein 1: understanding its role in chromatin assembly J. Biochem. 156, 11-20. doi:10.1093/jb/mvu032

Oda, H., Okamoto, I., Murphy, N., Chu, J., Price, S. M., Shen, M. M., TorresPadilla, M. E., Heard, E. and Reinberg, D. (2009). Monomethylation of histone $\mathrm{H} 4$-lysine 20 is involved in chromosome structure and stability and is essential fo mouse development. Mol. Cell. Biol. 29, 2278-2295. doi:10.1128/MCB.01768-08 Otterstrom, J., Castells-Garcia, A., Vicario, C., Gomez-Garcia, P. A., Cosma, M. P. and Lakadamyali, M. (2019). Super-resolution microscopy reveals how histone tail acetylation affects DNA compaction within nucleosomes in vivo. Nucleic Acids Res. 47, 8470-8484. doi:10.1093/nar/gkz593

Padeken, J., Zeller, P. and Gasser, S. M. (2015). Repeat DNA in genome organization and stability. Curr. Opin. Genet. Dev. 31, 12-19. doi:10.1016/j.gde. 2015.03.009

Peng, J. C. and Karpen, G. H. (2009). Heterochromatic genome stability requires regulators of histone H3 K9 methylation. PLoS Genet. 5, e1000435. doi:10.1371/ journal.pgen.1000435

Peters, A. H. F. M., O'Carroll, D., Scherthan, H., Mechtler, K., Sauer, K. S., Schöfer, C., Weipoltshammer, K., Pagani, M., Lachner, M., Kohlmaier, A et al. (2001). Loss of the Suv39h histone methyltransferases impairs mammalian 
heterochromatin and genome stability. Cell 107,323-327 doi:10.1016/S0092 8674(01)00542-6

Price, B. D. and D'Andrea, A. D. (2013). Chromatin remodeling at DNA doublestrand breaks. Cell 152, 1344-1354. doi:10.1016/j.cell.2013.02.011

Rechsteiner, M. and Hill, C. P. (2005). Mobilizing the proteolytic machine: cell biological roles of proteasome activators and inhibitors. Trends Cell Biol. 15, 27-33. doi:10.1016/j.tcb.2004.11.003

Saksouk, N., Simboeck, E. and Dejardin, J. (2015). Constitutive heterochromatin formation and transcription in mammals. Epigenet. Chromatin 8, 3. doi:10.1186/ 1756-8935-8-3

Saksouk, N., Hajdari, S., Perez, Y., Pratlong, M., Barrachina, C., Graber, C., Grégoire, D., Zavoriti, A., Sarrazi, A., Pirot, N. et al. (2020). The mouse HP1 proteins are essential for preventing liver tumorigenesis. Oncogene 39 2676-2691. doi:10.1038/s41388-020-1177-8

Sawyer, I. A., Bartek, J. and Dundr, M. (2019). Phase separated microenvironments inside the cell nucleus are linked to disease and regulate epigenetic state, transcription and RNA processing. Semin. Cell Dev. Biol. 90, 94-103. doi:10.1016/j.semcdb.2018.07.001

Schotta, G., Lachner, M., Sarma, K., Ebert, A., Sengupta, R., Reuter, G. Reinberg, D. and Jenuwein, T. (2004). A silencing pathway to induce H3-K9 and H4-K20 trimethylation at constitutive heterochromatin. Genes Dev. 18 1251-1262. doi:10.1101/gad.300704

Shoaib, M., Walter, D., Gillespie, P. J., Izard, F., Fahrenkrog, B., Lleres, D., Lerdrup, M., Johansen, J. V., Hansen, K., Julien, E. et al. (2018). Histone H4K20 methylation mediated chromatin compaction threshold ensures genome integrity by limiting DNA replication licensing. Nat. Commun. 9, 3704. doi:10.1038/ s41467-018-06066-8

Söderberg, O., Gullberg, M., Jarvius, M., Ridderstrale, K., Leuchowius, K.-J. Jarvius, J., Wester, K., Hydbring, P., Bahram, F., Larsson, L.-G. et al. (2006). Direct observation of individual endogenous protein complexes in situ by proximity ligation. Nat. Methods 3, 995-1000. doi:10.1038/nmeth947

Strom, A. R., Emelyanov, A. V., Mir, M., Fyodorov, D. V., Darzacq, X. and Karpen, G. H. (2017). Phase separation drives heterochromatin domain formation. Nature 547, 241-245. doi:10.1038/nature22989

Sun, L., Fan, G., Shan, P., Qiu, X., Dong, S., Liao, L., Yu, C., Wang, T., Gu, X., Li, Q. et al. (2016). Regulation of energy homeostasis by the ubiquitin-independen REGgamma proteasome. Nat. Commun. 7, 12497. doi:10.1038/ncomms 12497
Tardat, M., Murr, R., Herceg, Z., Sardet, C. and Julien, E. (2007). PR-Set7dependent lysine methylation ensures genome replication and stability through S phase. J. Cell Biol. 179, 1413-1426. doi:10.1083/jcb.200706179

Thiru, A., Nietlispach, D., Mott, H. R., Okuwaki, M., Lyon, D., Nielsen, P. R., Hirshberg, M., Verreault, A., Murzina, N. V. and Laue, E. D. (2004). Structural basis of HP1/PXVXL motif peptide interactions and HP1 localisation to heterochromatin. EMBO J. 23, 489-499. doi:10.1038/sj.emboj.7600088

Thomas, Y., Peter, M., Mechali, F., Blanchard, J.-M., Coux, O. and Baldin, V. (2014). Kizuna is a novel mitotic substrate for CDC25B phosphatase. Cell Cycle 13, 3867-3877. doi:10.4161/15384101.2014.972882

Verschure, P. J., van der Kraan, I., de Leeuw, W., van der Vlag, J., Carpenter, A. E., Belmont, A. S. and van Driel, R. (2005). In vivo HP1 targeting causes large-scale chromatin condensation and enhanced histone lysine methylation. Mol. Cell. Biol. 25, 4552-4564. doi:10.1128/MCB.25.11.4552-4564.2005

Welk, V., Coux, O., Kleene, V., Abeza, C., Trümbach, D., Eickelberg, O. and Meiners, S. (2016). Inhibition of proteasome activity induces formation of alternative proteasome complexes. J. Biol. Chem. 291, 13147-13159. doi:10. 1074/jbc.M116.717652

Wilk, S., Chen, W.-E. and Magnusson, R. P. (2000). Properties of the nuclear proteasome activator PA28 $\gamma(\mathrm{REG} \gamma)$. Arch. Biochem. Biophys. 383, 265-271. doi:10.1006/abbi.2000.2086

Wójcik, C., Tanaka, K., Paweletz, N., Naab, U. and Wilk, S. (1998). Proteasome activator (PA28) subunits, $\alpha, \beta$ and $\gamma$ (Ki antigen) in NT2 neuronal precursor cells and HeLa S3 cells. Eur. J. Cell Biol. 77, 151-160. doi:10.1016/S0171 9335(98)80083-6

Zannini, L., Lecis, D., Buscemi, G., Carlessi, L., Gasparini, P., Fontanella, E., Lisanti, S., Barton, L. and Delia, D. (2008). REG $\gamma$ proteasome activator is involved in the maintenance of chromosomal stability. Cell Cycle 7, 504-512. doi:10.4161/cc.7.4.5355

Zannini, L., Buscemi, G., Fontanella, E., Lisanti, S. and Delia, D. (2009). REG $\gamma /$ PA28 $\gamma$ proteasome activator interacts with PML and Chk2 and affects PML nuclear bodies number. Cell Cycle 8, 2399-2407. doi:10.4161/cc.8.15.9084

Zeng, W., Ball, A. R., Jr. and Yokomori, K. (2010). HP1: heterochromatin binding proteins working the genome. Epigenetics 5, 287-292. doi:10.4161/epi.5.4.11683

Zhang, Z. and Zhang, R. (2008). Proteasome activator PA28 $\gamma$ regulates p53 by enhancing its MDM2-mediated degradation. EMBO J. 27, 852-864. doi:10.1038/ emboj.2008.25 
A
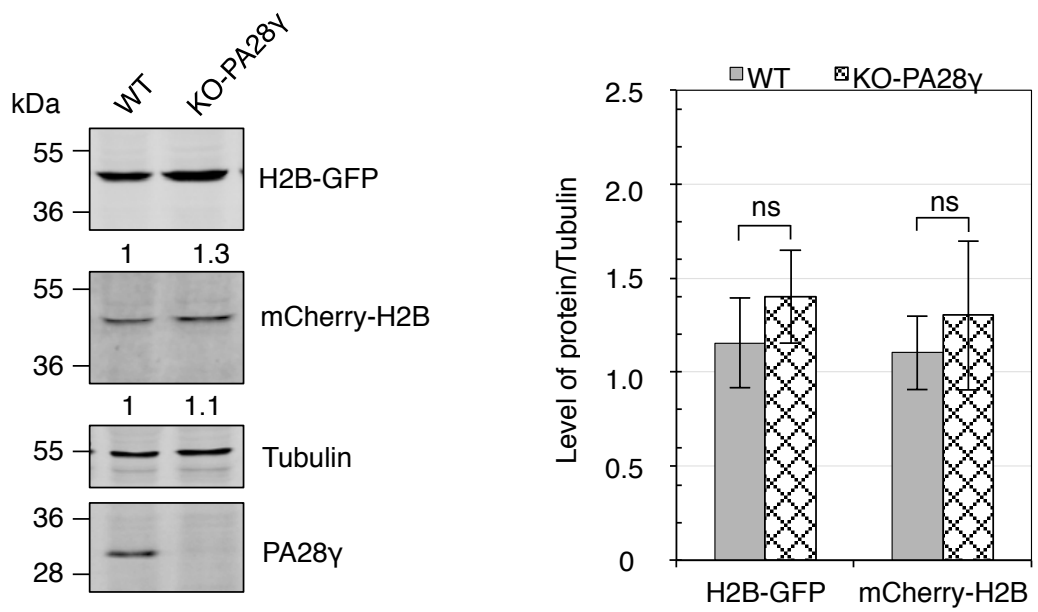

B
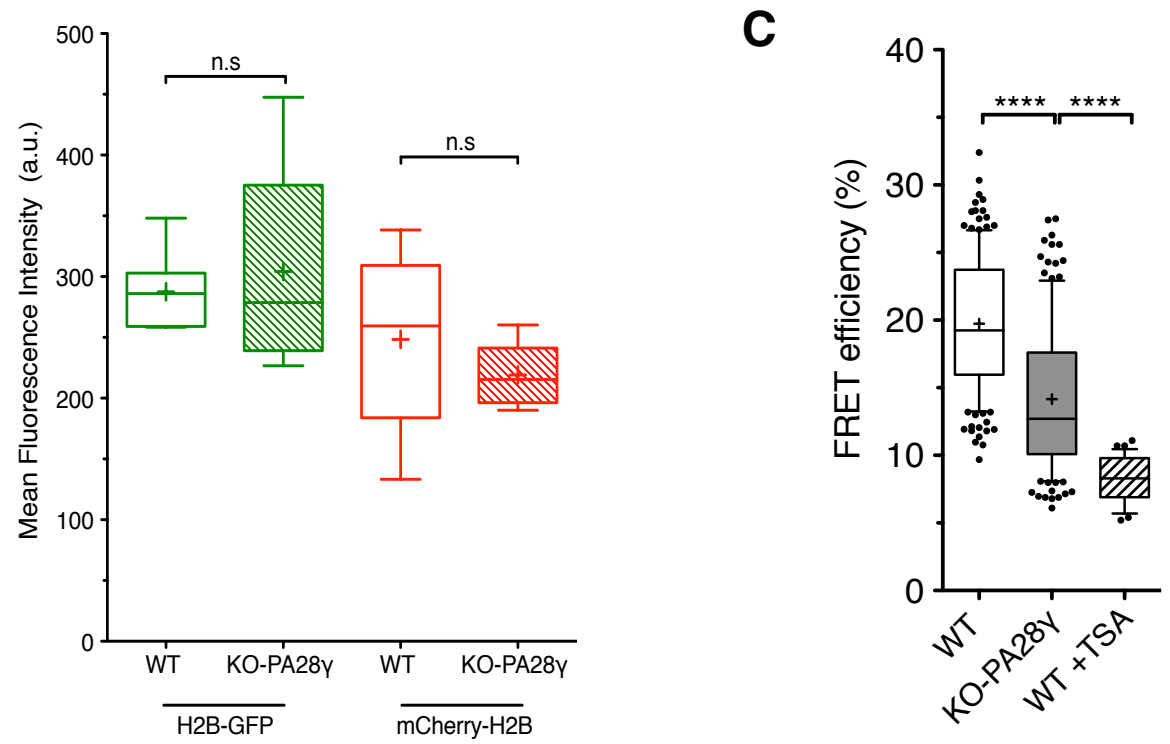

Figure S1. PA28 $\gamma$-depletion does not alter the expression level of H2B-GFP or mCherryH2B.

A. Immunoblot analysis of H2B-GFP and mCherry-H2B expression level in total extracts from parental (WT) and $\mathrm{KO}-\mathrm{PA} 28 \gamma \mathrm{HeLa}^{\mathrm{H} 2 \mathrm{~B}-2 \mathrm{FPs}}$ cells (left panel). Tubulin was used as a loading control. The relative abundance of $\mathrm{H} 2 \mathrm{~B}$ proteins was quantified using ImageJ software. Graphical representation of the relative abundance of H2B-GFP and mCherry-H2B, detected with an anti-GFP and anti-RFP, respectively, and normalized to tubulin (right panel). The mean $\pm \mathrm{SD}$ is from four independent experiments. Statistical significance was evaluated based on Student's $t$-test, $\mathrm{ns}=$ not significant $(p=0.2027$ and 0.4024 for H2B-GFP and mCherry-H2B, respectively).

B. Quantification of the H2B-GFP and mCherry-H2B fluorescence intensities in WT and KOPA28 $\gamma \mathrm{HeLa}^{\mathrm{H} 2 \mathrm{~B}-2 \mathrm{FPs}}$ cells. The total number of cells analyzed is $n=172$ (WT), $n=183$ (KOPA28 $\gamma$ ). Statistical significance was evaluated with Student's $t$-test, ns $=$ not significant.

C. FRET analysis in WT, KO-PA28 $\gamma \mathrm{HeLa}^{\mathrm{H} 2 \mathrm{~B}-\mathrm{FPs}}$ cells, and WT HeLa ${ }^{\mathrm{H} 2 \mathrm{~B}-\mathrm{FPs}}$ cells treated with Trichostatin A (TSA, 200ng/ml, $24 \mathrm{~h}$ ). The statistical analysis of the mean FRET efficiency percentage is presented as box-and-whisker plots. The thick line represents median, the boxes correspond to the mean FRET values above and below the median, with the whiskers covering the 10-90 percentile range. The total number of nuclei analyzed is $n=154$ (WT), $n=132$ (KOPA28 $\gamma$ ), and $n=33$ (WT + TSA), $* * * * p<0.0001$ (Student's $t$-test). 


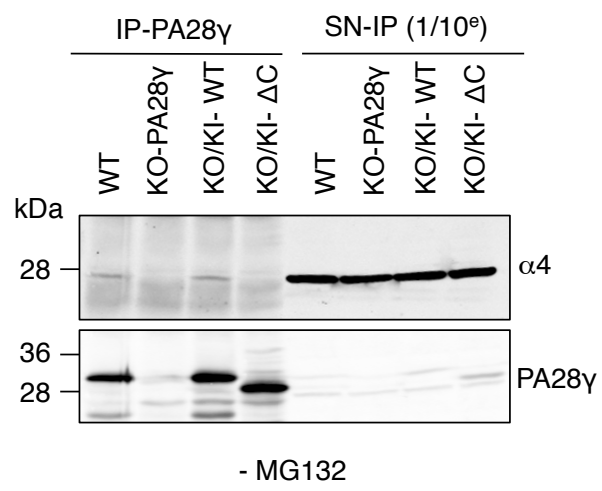

Figure S2. PA28 $\gamma-\Delta C$-mutant does not interact with the $20 S$ proteasome.

Whole-cell extracts from parental $\mathrm{HeLa}^{\mathrm{H} 2 \mathrm{~B}-2 \mathrm{FPs}}$ (WT), PA28 $\gamma$-knockout (KO-PA28 $\gamma$ ) cells and $\mathrm{KO}$ cells re-expressing the wild-type (KO/KI-WT\#8) form or the $\Delta \mathrm{C}$ mutant $(\mathrm{KO} / \mathrm{KI}-\Delta \mathrm{C})$ of PA28 $\gamma$ were subjected to immunoprecipitation using antiPA28 $\gamma$ antibodies. Immunoblots of the pull-down (IP-PA28 $\gamma$ ) and the supernatant (SN-IP, $\left.1 / 10^{\mathrm{eme}}\right)$ from whole-cell extracts were probed with the antibodies indicated. 
A

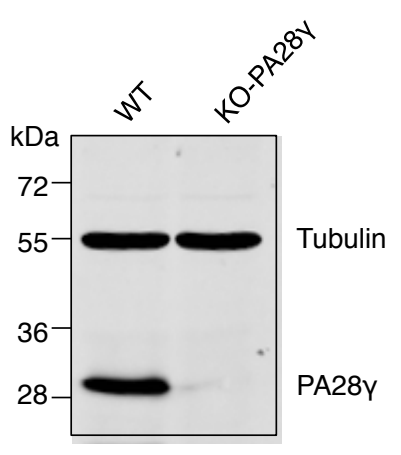

C

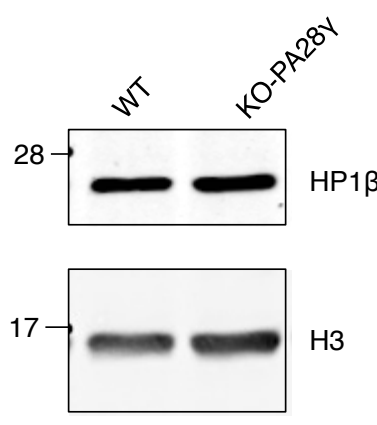

D
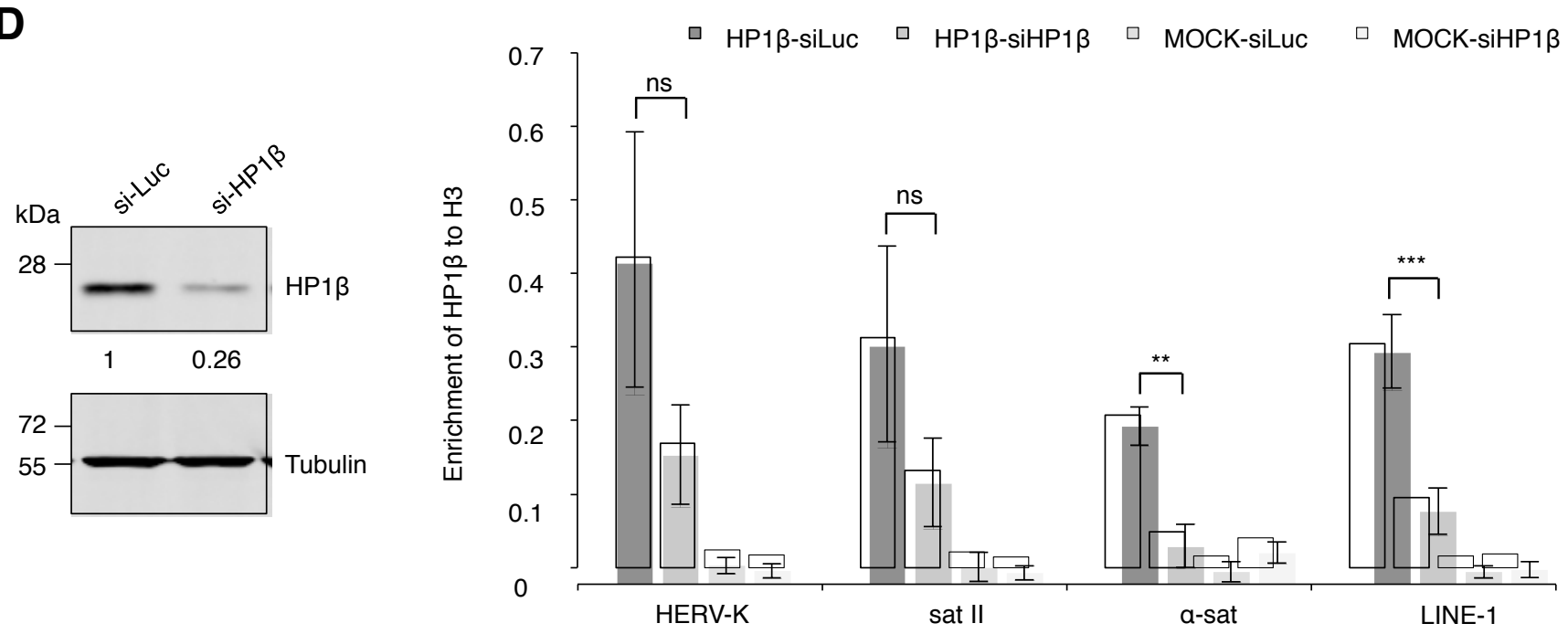

B
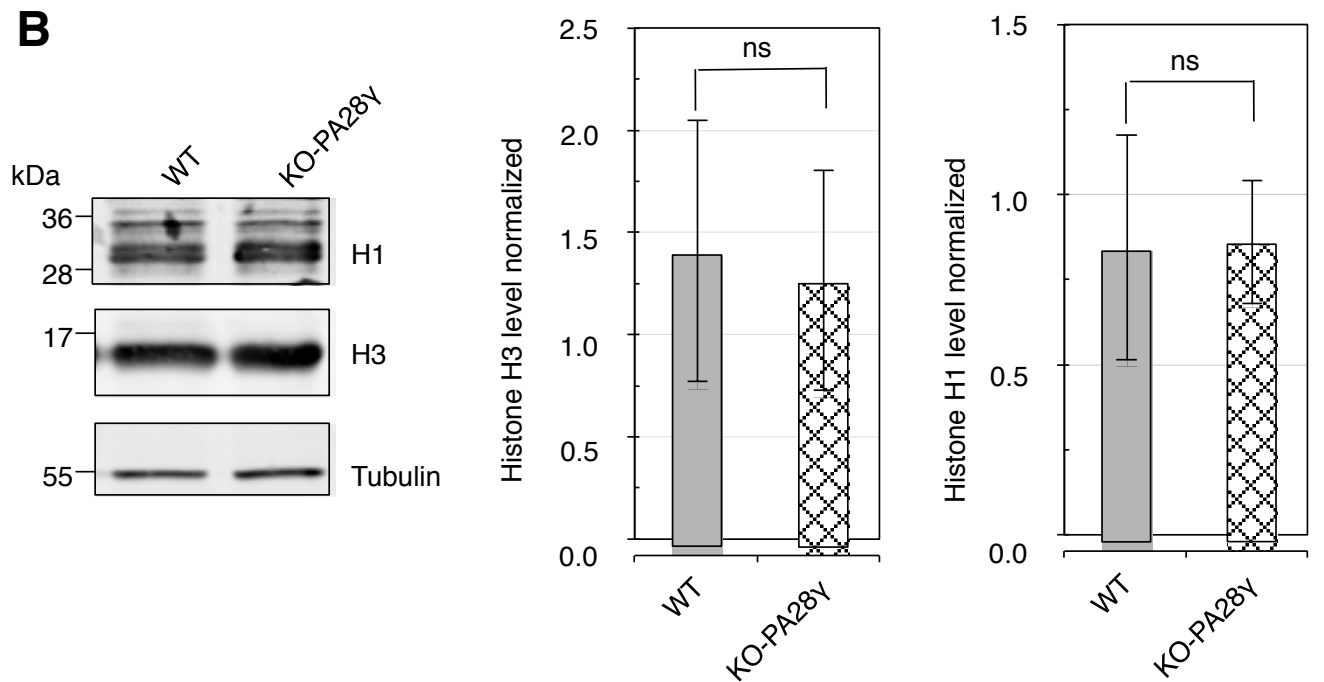

Figure S3 
Figure S3. PA28 $\gamma$-depletion does not affect H1, H3 or HP1 $\beta$ expression level and HP1 $\beta$ is present at the same repetitive elements than PA28 $\gamma$.

A. Immunoblot of whole-cell extract $(30 \mu \mathrm{g})$ from asynchronous parental (WT) and KOPA28 $\gamma$ (KO-PA28 $\gamma$ ) U2OS cells, using anti-PA28 $\gamma$. Tubulin was used as a loading control.

B. Immunoblot analysis of histone $\mathrm{H} 3$ and $\mathrm{H} 1$ expression level in total extracts from WT and KO-PA28 $\gamma$ U2OS cells (left panel). Tubulin was used as a loading control. The relative abundance of histone $\mathrm{H} 3$ and $\mathrm{H} 1$ proteins was quantified using ImageJ software. Graphical representation of the relative abundance of histone $\mathrm{H} 3$ and $\mathrm{H} 1$ normalized to tubulin and histone $\mathrm{H} 3$, respectively (right panel). The mean $\pm \mathrm{SD}$ is from four independent experiments. Statistical significance was evaluated based on Student's $t$-test, ns $=$ not significant. ( $p=0.7560$ and 0.92033 for $\mathrm{H} 3$ and $\mathrm{H} 1$, respectively).

C. Immunoblot analysis of HP1 $\beta$ expression level in total extracts from WT and KO-PA28 $\gamma$ U2OS cells (left panel). Histone H3 was used as a loading control. Graphical representation of the relative abundance of HP1 $\beta$ normalized to histone H3 (right panel). The mean \pm SD is from three independent experiments. Statistical significance was evaluated based on Student's $t$-test, $\mathrm{ns}=$ not significant $(p=0.99619)$.

D. Immunoblot analysis of HP1 $\beta$ expression level in total extracts from U2OS cells treated or not with si-HP1 $\beta$ (left panel). Tubulin was used as a loading control. The relative abundance of HP1 $\beta$ proteins was quantified using ImageJ software. ChIP-qPCR analysis of HP1 $\beta$ levels at different repetitive elements (as indicated on the X-axis) in U2OS cells treated with si-Luc or si-HP1 $\beta$. Data are represented as relative enrichment of HP1 $\beta$ versus histone H3 control, as shown on the y-axis (right panel). Data are means +/- SEM $(n=5)$. Significance was calculated using Student's $t$-test, $\mathrm{ns}=$ not significant, $* p<0.05$, ** $p<$ 0.01 and $* * * p<0.001 . p$-values are presented in Table S2. 
A
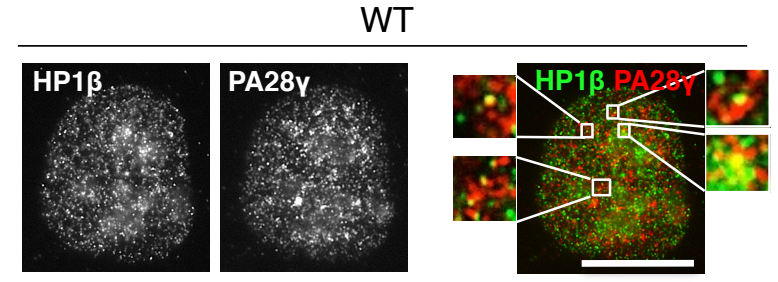

KO-PA28Y

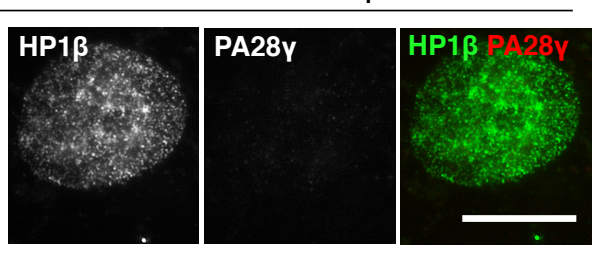

B
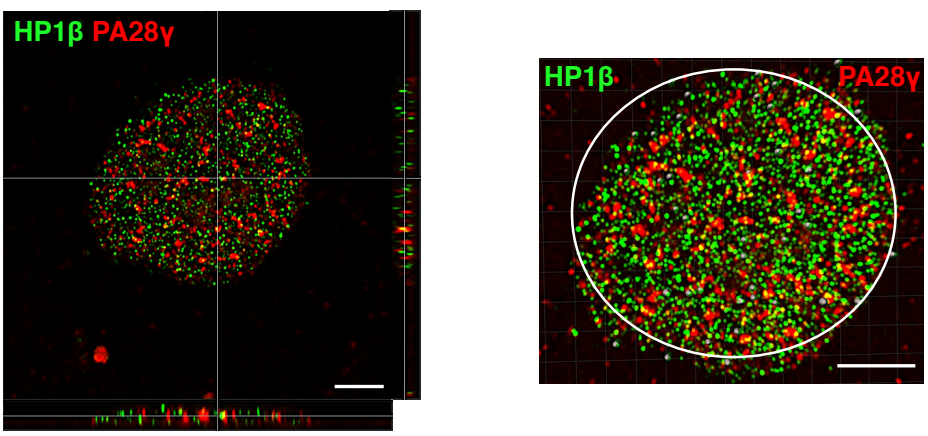

Co-localization HP1ß/PA28y

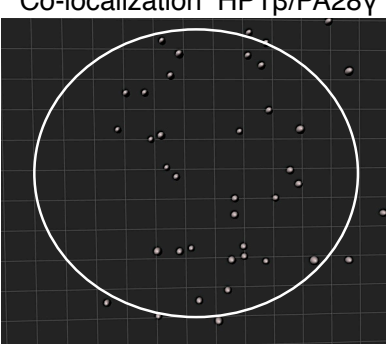

C
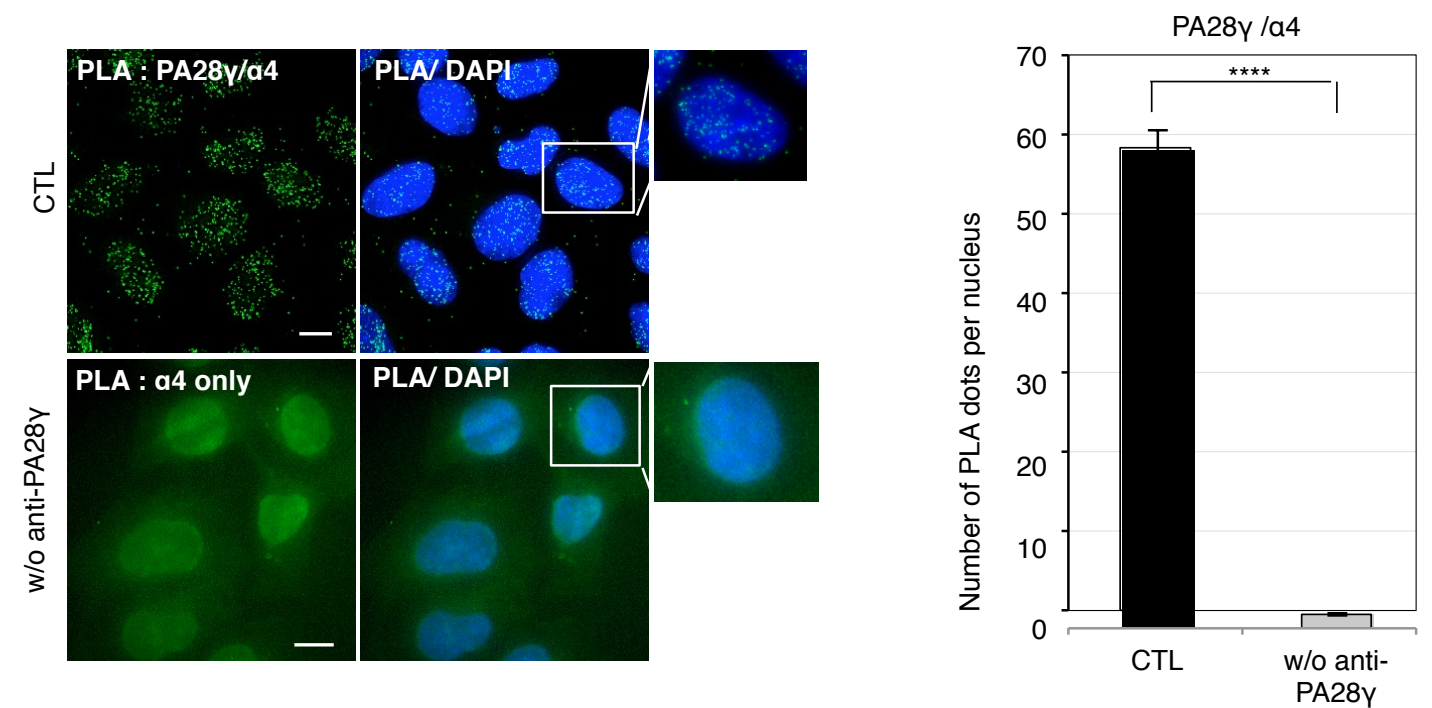

D

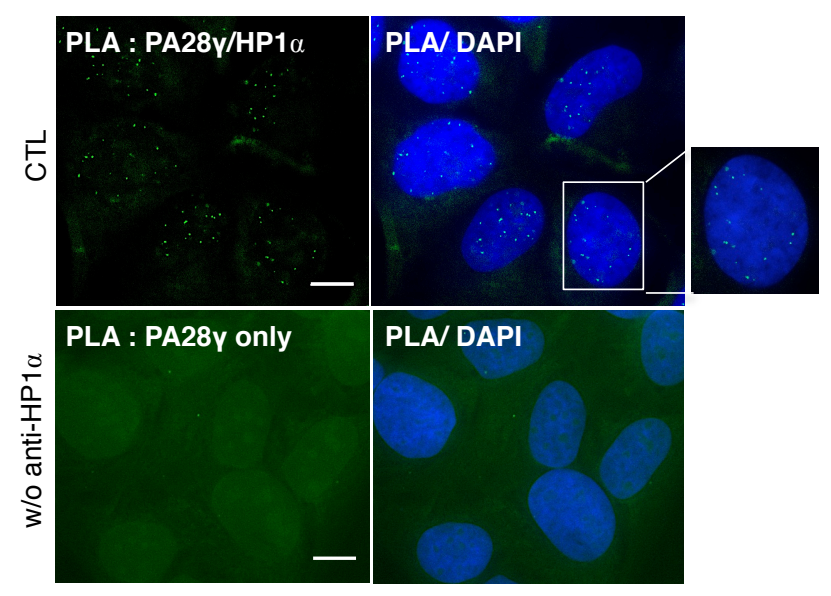


Figure S4. Co-localization of a fraction of PA28 $\gamma$ with HP1 $\beta$ and HP1 $\alpha$.

A. Asynchronously-growing wild-type (left panel) and KO-PA28 $\gamma$ (right panel) U2OS cells were pre-permeabilized with $0.5 \%$ Triton-X100 to extract soluble proteins before fixation and the detection of endogenous HP1 $\beta$ and PA28 $\gamma$ by indirect immunofluorescence using anti-HP1 $\beta$ and PA28 $\gamma$ antibodies. Representative merged images of HP1 $\beta$ (green) and PA28 $\gamma$ (red) are shown (right panels), higher-magnification views are shown for U2OS-WT cells. Scale bars, $10 \mu \mathrm{m}$.

B. A representative Airyscan confocal Z-projected image showing the co-detection of HP1 $\beta$ (green) and PA28 $\gamma$ (red) (left) in U2OS cells treated as in A. Co-localizations of both proteins along the cross are shown (left panel). Scale bars, $5 \mu \mathrm{m}$. Using the co-localization module of Imaris, a representative image of HP1 $\beta$ (green), PA28 $\gamma$ (red) corresponding to a 3D image (middle panel) is shown with the corresponding image showing only colocalization spots (white/grey, right panel). Scale bars, $5 \mu \mathrm{m}$.

C. In situ proximity ligation assay (is-PLA) was carried out in asynchronous U2OS cells using primary antibodies directed against PA28 $\gamma$ (rabbit polyclonal) and the $\alpha 4$ subunit of the 20S proteasome (mouse monoclonal) (CTL) or with $\alpha 4$ and without PA28 $\gamma$ antibodies (w/o anti-PA28 $\gamma$ ) and DNA was stained with DAPI. Positive PLA signals appear as green dots and higher magnification views of a nucleus are shown (left panel). Scale bars, $10 \mu \mathrm{m}$. The number of PLA dots per nucleus in cells treated with both antibodies (CTL) or with only $\alpha 4$ antibodies (w/o anti-PA28 $\gamma$ ) is shown on the bar graph (right panel). Data represent the mean \pm SD from 3 independent experiments, the number of cells analyzed was $n=38$ and $n=42$ in control cells and cells treated without primary PA28 $\gamma$ antibody, respectively. The $p$-value was determined using Student's $t$-test, $* * * * p \leq 0.0001$.

D. Is-PLA was carried out in U2OS cells using primary antibodies directed against PA28 $\gamma$ (mouse monoclonal) and HP1 $\alpha$ (rabbit polyclonal) (CTL) or with PA28 $\gamma$ and without HP1 $\alpha$ antibodies (w/o anti-HP1 $\alpha$ ) and DNA was stained with DAPI. Positive PLA signals appear as green dots and a higher magnification view of a nucleus is shown (left panel). The number of PLA dots per nucleus in cells treated with both antibodies (CTL) or with only PA28 $\gamma$ antibodies (w/o anti-HP1 $\alpha$ ) is shown on the bar graph (right panel). Data represent the mean \pm SD from 3 independent experiments, the number of cells analyzed was $n=40$ and $n=41$ in control cells and cells treated without primary HP1 $\alpha$ antibody, respectively. The $p$-value was determined using Student's $t$-test, $* * * * p \leq 0.0001$ ). 
A

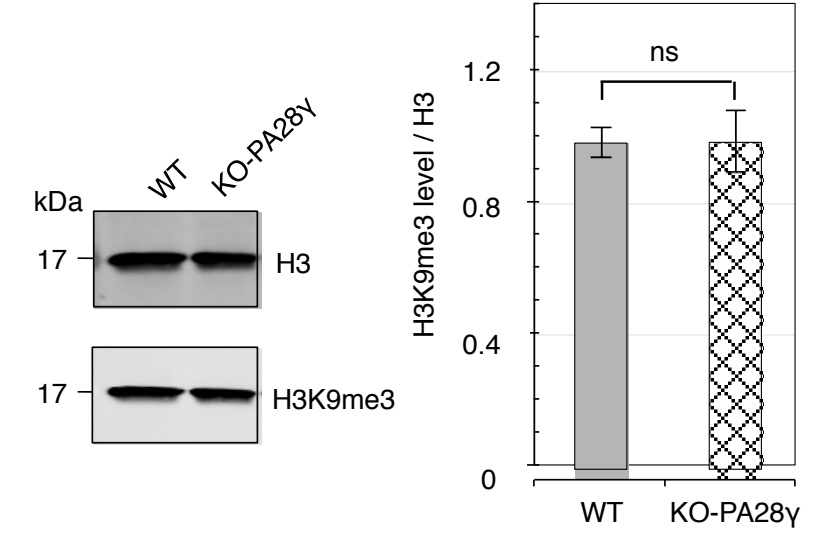

C

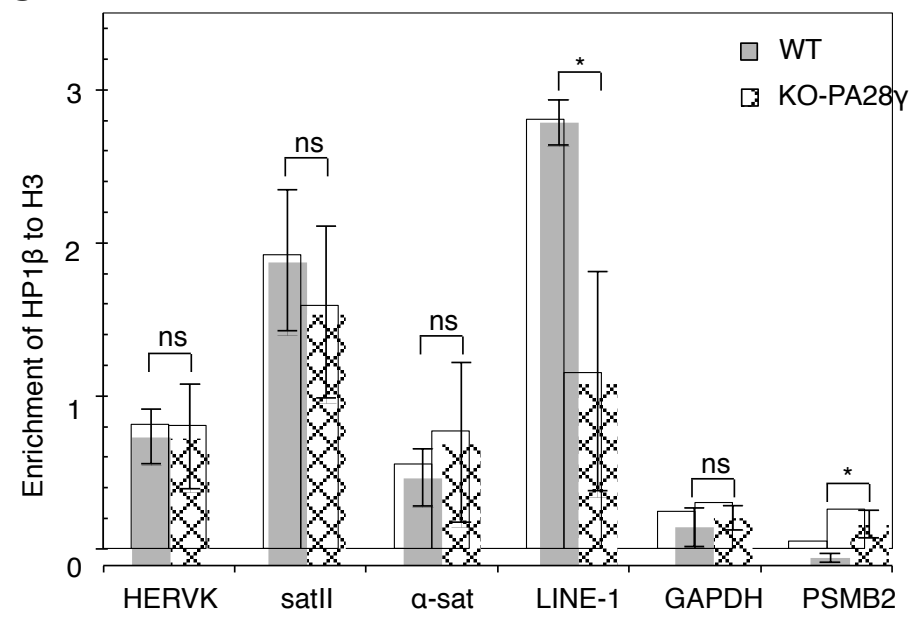

B
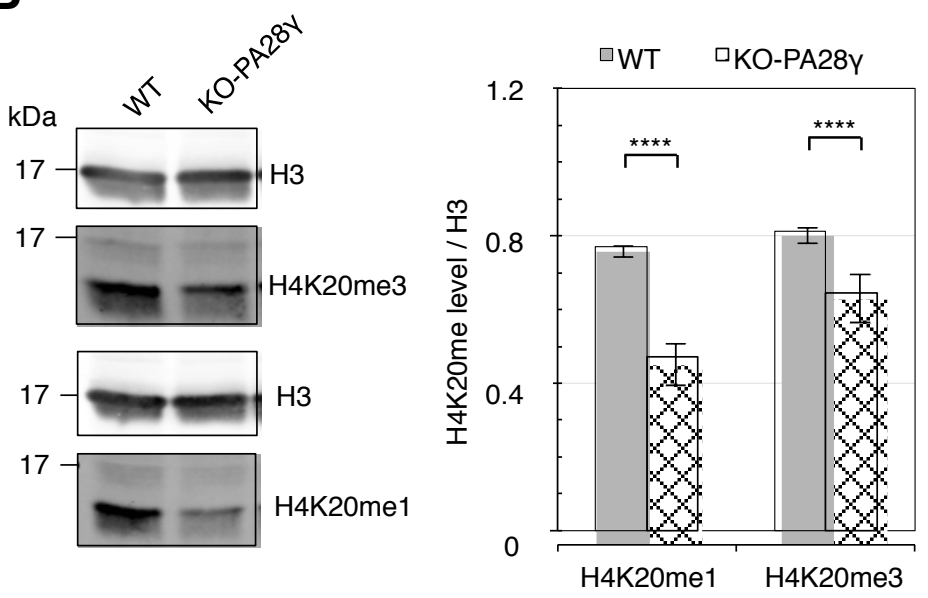

D

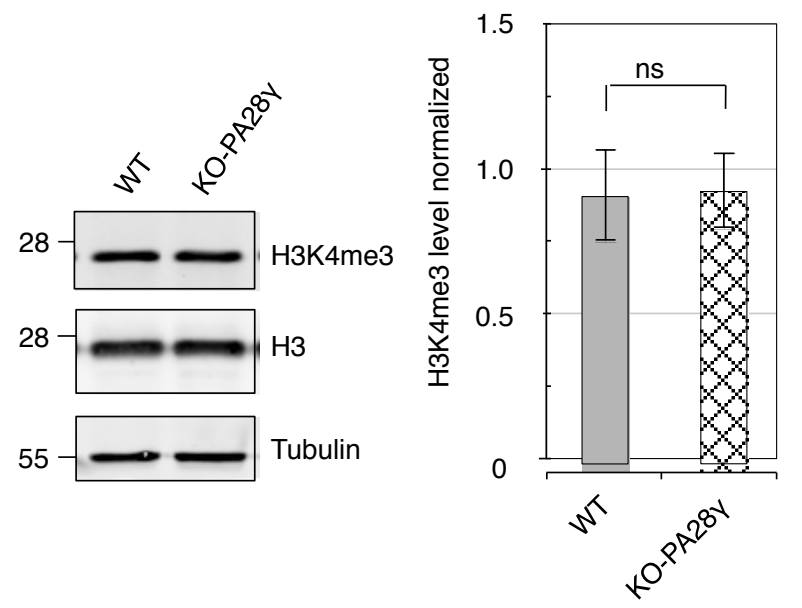

E

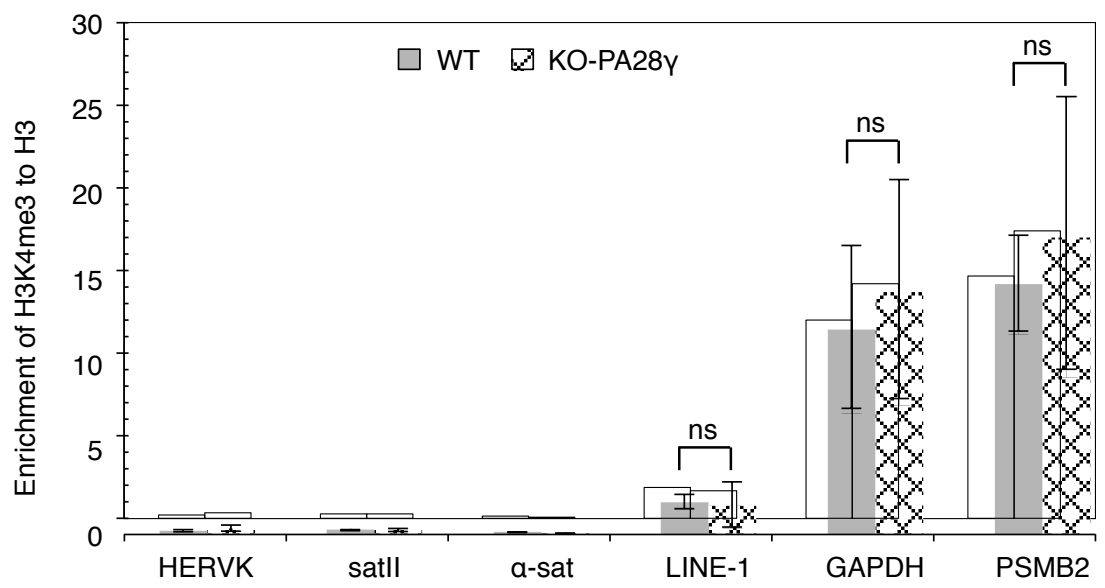


Figure S5. PA28 $\gamma$ loss has neither a global effect on H3K9me3, H4K20me3 and H3K4me3 protein level nor on HP1 $\beta$-binding and H3K4me3 mark at repetitive DNA sequences and genes.

A. Representative immunoblots of whole-cell extracts from U2OS (WT and KO-PA28 $\gamma$ ) cells, using anti-H3K9me3 antibodies. Histone H3 was used as loading control. Graphical representation of the relative abundance of the tri-methylation (H3K9me3) mark on histone $\mathrm{H} 3$ normalized to histone $\mathrm{H} 3$. The mean \pm SD is from four independent experiments. The $p$ value was determined using a Student's $t$-test, ns $=$ not significant $(p=0.9354)$.

B. Immunoblots of whole-cell extracts from U2OS (WT and KO-PA28 $\gamma$ ) cells, using antiH4K20me3 and anti-H4K20me1 antibodies. Histone H3 was used as loading control. Graphical representation of the relative abundance of the mono-methylation (H4K20me1) and the tri-methylation (H4K20me3) marks on histone $\mathrm{H} 4$ normalized to histone $\mathrm{H} 3$. The mean $\pm \mathrm{SD}$ is from four independent experiments. The $p$-value was determined using Student's $t$-test, $* * * * p \leq 0.0001$ ( $p=2.091 .74 \mathrm{E}-07$ and $p=9.25 \mathrm{E}-05$ for H4K20me1 and H4K20me3, respectively).

C. ChIP-qPCR analysis of HP1 $\beta$ levels at different repetitive elements and genes (as indicated on the X-axis) in WT versus KO-PA28 $\gamma$ U2OS cells. Data are represented as relative enrichment of HP1 $\beta$ antibody versus histone $\mathrm{H} 3$ control, as shown on the $\mathrm{y}$-axis. Data are means + /- SEM $(n=3)$. Significance was calculated by Student's $t$-test, ns $=$ not significant, $(p=0.9809, p=0.4746, p=0.5446$ and $p=0.5554$ for HERV-K, SatII, $\alpha-$ Sat and GAPDH respectively), ${ }^{*} p<0.05$ ( $p=0.01723$ and $p=0.01763$ for LINE-1 and PSMB2, respectively).

D. Representative immunoblots of whole-cell extracts from U2OS (WT and KO-PA28 $\gamma$ ) cells, using anti-H3K4me3 antibodies. Histone H3 was used as loading control. Graphical representation of the relative abundance of the tri-methylation (H3K4me3) mark on histone $\mathrm{H} 3$ normalized to histone $\mathrm{H} 3$. The mean $\pm \mathrm{SD}$ is from four independent experiments. The $p$ value was determined with a Student's $t$-test, ns $=$ not significant $(p=0.9354)$.

E. ChIP-qPCR analysis of H3K4me3 levels at different repetitive elements and genes (as indicated on the X-axis) in WT versus KO-PA28 $\gamma$ U2OS cells. Data are represented as relative enrichment of $\mathrm{H} 3 \mathrm{~K} 4 \mathrm{me} 3$ versus histone $\mathrm{H} 3$ control as shown on the $\mathrm{y}$-axis. Data are means $+/$ - SEM $(n=3)$. Significance was calculated by Student's $t$-test, $\mathrm{ns}=$ not significant ( $p=0.8453, p=0.8116, p=0.1863$ and $p=0.4721$ for, LINE-1, GAPDH and PSMB2, respectively). 


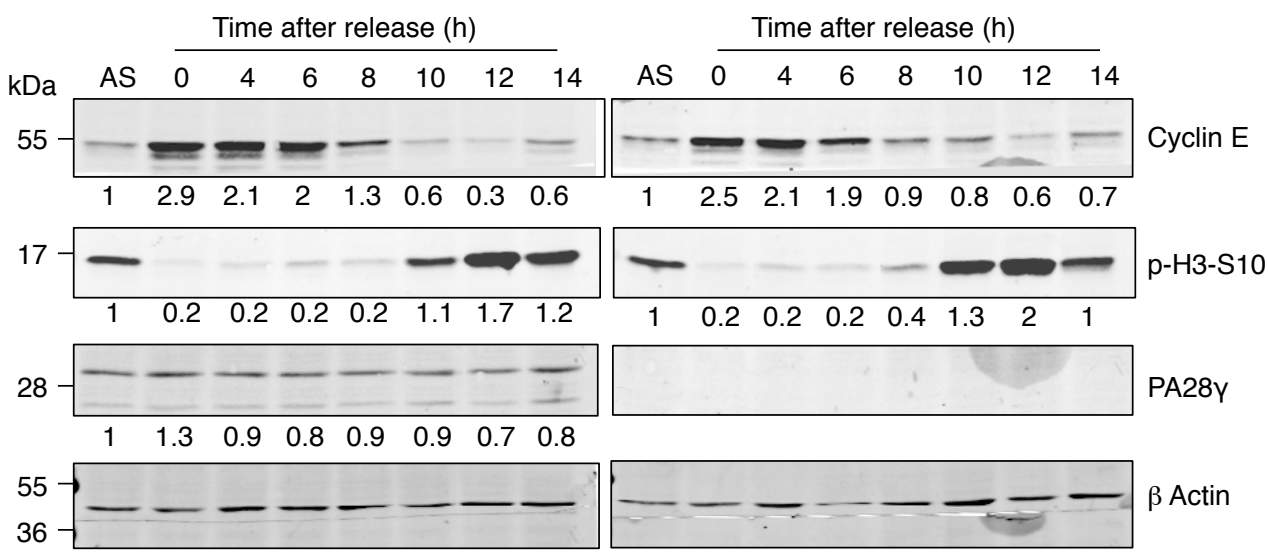

Figure S6. PA28 $\gamma$ depletion decreases the $S$ phase duration.

Immunoblot of total cell extracts from asynchronous parental (WT) and KO-PA28 $\gamma$ U2OS cells (AS), and cells synchronized at the G1/S phase transition by a double thymidine block (0) and released for the times indicated. After SDS-PAGE, proteins were transferred to PVDF membrane. Each membrane (WT and KO-PA28 $\gamma$ ) was cut just above the $36 \mathrm{kDa}$ molecular weight marker. Upper parts were first incubated with anti-CycE antibodies (mouse monoclonal, sc-247, Santa Cruz) and lower parts incubated with anti-PA28 $\gamma$ antibodies (mouse), and then revealed with a secondary goat anti-mouse antibody (DyLight 488). In a second step, lower parts were incubated with anti-phospho-Histone H3-S10 antibodies (rabbit mAb, \#53348, Cell Signaling) and revealed with a secondary goat antirabbit antibody (DyLight 488). Finally, upper and lower parts of the membrane were incubated with anti- $\beta$-actin antibodies and revealed with a secondary goat anti-rabbit antibody (Dylight 800), $\beta$-actin was used as a loading control. 
Table S1: $p$ values of the figure $6 A, B(C h I P)$

\begin{tabular}{|c|c|c|}
\hline & $\begin{array}{c}\text { T-test (H3K9me3/H3) } \\
\text { U2OS vs KO PA28Y }\end{array}$ & $\begin{array}{c}\text { T-test (H4K20me3/H3) } \\
\text { U2OS vs KO PA28Y }\end{array}$ \\
\hline HERV-K & $6.47871 \mathrm{E}-06$ & 0.009044059 \\
\hline Sat II & $8.6538 \mathrm{E}-06$ & $1.37015 \mathrm{E}-05$ \\
\hline$\alpha$-sat & 0.00014585 & 0.001004765 \\
\hline LINE-1 & $2.80855 \mathrm{E}-05$ & 0.002330735 \\
\hline GAPDH & 0.677649943 & 0.003366684 \\
\hline PSMB2 & 0.000677637 & 0.121036886 \\
\hline CCNA2 & 0.848275718 & 0.066976205 \\
\hline CCNE2 & 0.803674003 & 0.835817889 \\
\hline
\end{tabular}

Table S2: $p$ values of the figure S3D (ChIP)

\begin{tabular}{|c|c|}
\hline & T-test (HP1 $\beta$ ) U2OS si-Luc vs si-HP1 $\beta$ ) \\
\hline HERV-K & $\begin{array}{r}0.057078569 \\
\end{array}$ \\
\hline Sat II & 0.066693611 \\
\hline$\alpha$-sat & 0.005250998 \\
\hline LINE-1 & 0.000382203 \\
\hline
\end{tabular}

Table S3: $p$ values of the figure 6C (determined with the 2-way ANOVA)

\begin{tabular}{|c|c|c|c|c|c|c|}
\hline $\begin{array}{c}\text { Time after } \\
\text { release (hours) }\end{array}$ & 0 & 4 & 6 & 8 & 10 & 12 \\
\hline S-phase & 0.6759 & 0.0052 & $<0.0001$ & $<0.0001$ & $>0.9999$ & 0.0377 \\
\hline G2/M-phase & 0.9946 & 0.0187 & $<0.0001$ & $<0.0001$ & $<0.0002$ & $<0.0001$ \\
\hline
\end{tabular}

